\title{
Image reconstruction methods for the PBX-M pinhole camera
}

\author{
A. Holland, E. T. Powell, and R. J. Fonck \\ Princeton Plasma Physics Laboratory, Princeton University \\ P.O. Box 451, Princeton, NJ 08543
}

This paper describes two methods which have been used to reconstruct the soft X-ray emission profile of the PBX-M tokamak from the projected images recorded by the PBX-M pinhole camera. ${ }^{1}$ Both methods must accurately represent the shape of the reconstructed profile while also providing a degree of immunity to noise in the data.

The first method is a simple least squares fit to the data. This has the advantage of being fast and small, and thus easily implemented on the PDP. 11 computer used to control the video digitizer for the pinhole camera.

The second method involves the application of a maximum entropy algorithm to an overdetermined system. This has the advantage of allowing the use of a default profile. This profile contains additional knowledge about the plasma shape which can be obtained from equilibrium fits to the external magnetic measurements. Additionally the reconstruction is guaranteed positive, and the fit to the data can be relaxed by specifying both the amount and distribution of noise in the image. The algorithm described has the advantage of being considerably faster, for an overdetermined system, than the usual Lagrange multiplier approach ${ }^{2,3}$ to finding the maximum entropy solution. 


\section{Introduction}

The PBX-M pinhole camera provides a toroidally integrated view from a point on the outer midplane of the PBX-M plasma, as shown in Fig. 1. The X-ray emission profile is generally a bean-shaped toroid and the goal of the reconstruction procedure is to obtain the emission profile over a poloidal section through the toroid. For this application the features of interest are the shapes of the contours of constant $X$-ray emission since they can then be used to infer the internal magnetic properties of the plasma. ${ }^{4}$

\section{A. General features of both reconstruction methods}

1. The emission profile is assumed to be toroidally symmetric.

2. The camera supplies a $128 \times 128$ pixel image which is reduced to a $32 \times 32$ image of 1024 pixels for the subsequent analysig.

3. Each pixel samples the emission from a volume of plasma which is determined simply by the projection of the pixel through a pinhole aperture.

The nature of the projection provided by this geometry is such that the the number of pixeis sampling a toroidal ring of plasma with a small cross section increases greatly as the center of the ring's cross section is moved closer to the midplane and closer to the outer edge of the plasma. Fig. 2 shows contours of the function specifying total contribution of each region in a poloidal section of the plasma to the projected image. This means that the reconstructed emissic 1 profile is very well detsrmined near the outer midplane and is progressively more sensitive to noise in the data in regions which are further from the inidplane and closer to the center of the torus.

\section{B. Formulation of the problem}

The emission profile is specified as a set of $\left\{E_{c}\right\}$ values assigned to $N C$ toroidal rings with a rectangular cross section. Each value $E_{c}$ is the emission per unit volume of the source averaged over ring $c$. In order to provide good shape resolution near the center of the plasma while maintaining an 
acceptably low sensitivity to noise in the data, the emission profile is specified on a dual resolution grid which has smaller cells in the outer midplane region. In addition, cells which are in regions with no plasma or cells which are hidden from view are eliminated. This results in the bean-shaped grid shown in Fig. 3 which shows a poloidal section through a grid of 130 rings.

The emission values $\left\{E_{c}\right\}$ are mapped linearly onto the $N P$ pixels of the camera image $\left\{I_{p}\right\}$ by the usual imaging equations

$$
I_{p}=\sum_{c=1}^{v C} S_{p c} E_{c}+\pi_{p}
$$

The elements $S_{p c}$ of the $N P \times N C$ matrix $S$ are computed from the geometry of the system and represent the sensitivity of pixel $p$ to the emission from cell $c$. The values $\left\{n_{p}\right\}$ represent the noise in the data.

\section{Least squares method}

Since the problem has been formulated as an overdetermined system with 1023 image pixels and only 130 emission cells, the emission profile can be recovered by a simple least squares $f t^{5}$ which minimizes $\sum n_{p}^{2}$. The emission vector $\mathbf{E}$ is computed from the image vector I by multiplication by the generalized inverse of $\mathbf{S}$.

$$
E=\left(S^{T}\right)^{-1} S^{T} \mathbf{I}=\mathbf{M I}
$$

The inverse matrix $\mathbf{M}$ is computed once for a given reconstruction grid and camera geometry and then saved for repeated use. Since computing the emission profile for each image just involves multiplying a matrix by a vector. the algorithm can easily be implemented and is relatively fast.

\section{A. Negative values}

The most obvious problem with the method is that it allows solutions with negative values for the emissions $\left\{E_{c}\right\}$. Negative values are caused by noise in the data or numerical errors in the matrix inversion and multiplication. Since they usually occur in cells near regions in the original source with small 
or zero emission. we remove them from the final solution by assigning them to zero or to a small percentage of the average emission of the solution.

\section{B. Smoothing}

We also tested the effect of applying smoothing to the reconstructed emission profile obtained from the least squares method. The smoothing procedure is described as follows.

1. Obtain the emission at any point $E(r, Z)$ from the reconstructed $\left\{E_{c}\right\}$ using bilinear interpolation from the centers of the surrounding cells.

2. Compute the average value $E(r, Z)$ for each cell.

3. Set the emissions $\left\{E_{c}\right\}$ equal to the average values from step 2 .

The effect of this procedure is to apply a longer scale length smoothing in regions of the grid containing larger cells. Stronger smoothing is obtained by applying the procedure several times.

\section{Tests}

Test data were constructed by specifying a set of emissions $\left\{E_{c}\right\}$ which describe a suitable test source and then computing the corresponding image $\left\{I_{p}\right\}$ using Eqs. (1). The noise vaiues $\left\{n_{p}\right\}$ were simulated using a Gaussian random noise generator. A global estimate of the accuracy is the R.MS deviation from the original source defined as

$$
\Delta_{r m s}=\frac{100}{E^{\text {reconstructed }}} \times \sum_{i=1}^{v C}\left(E^{\text {weconstructed }}-E_{r}^{\text {original }}\right)^{2} \% \text {, }
$$

where $\bar{E}$ reconstsucted is the average ronnstructed emission.

The result is shown in Fig. i f, ? :, wh wh a standard deviation equal to $10 \%$ of the average signal applieil .....th ignal value. The original source is shown in Fig. 5 and the cell grui :- -.., wn in Fig. 3. Smoothing can improve the appearance and R.MS devist:... . $1^{\prime}$ the expense of spatial resolution as shown in Fig. 6. 
Even though the system is $8[\approx(1024$ image pizels $) /(130$ cells $)]$ times overdetermined, it is still quite sensitive to noise. It is possible to obtain a better result by giving up spatial resolution in less overdetermined regions of the source beforehand by using a more overdetermined cell grid shown in Fig. 7 . This grid, which contains 76 cells, is 13.5 times overdetermined. The result for the same noise and source is shown in Fig. 8.

\section{Effect of smoothing}

Although smoothing improves the RMS deviation and appearance of the result, it does so because the original source is relatively smooth. The smoothing procedure is rather arbitrary since it does not take into account the original imaging Eqs. (1) For the system. During smoothing the noise for each signal $n_{p}$ can assume any value, and the emission assigned to a cell does not depend on the constraints imposed by the imaging equations. No account is taken of how overdetermined the value of a particular cell may be except for the fact that a shorter scale length smoothing is applied in the higher resolution parts of the grid.

The maximum entropy method described next guarantees a positive definite solution and also allows for smoothing, which is consistent with the imaging equations and the statistics of the noise values $\left\{n_{p}\right\}$.

\section{Maximum entropy method}

\section{A. Introduction}

As shown by Frieden ${ }^{6}$ the maximum entropy method is a maximum likelihood estimator derived from the requirement that we select the solution which has maximum probability for given noise and object statistics.

$$
P^{\text {abject }}\left(\left\{E_{c}\right\}\right) P^{\text {noise }}\left(\left\{n_{p}\right\} \mid\left\{E_{c}\right\}\right)=\text { maximum. }
$$

prorse $\left(\left\{n_{p}\right\} \mid\left\{E_{c}\right\}\right)$ is the probability of a given set of noise values $\left\{n_{p}\right\}$, given a particular object $\left\{E_{c}\right\}$. For Gaussian noise statistics 


$$
P^{\text {noise }}\left(\left\{n_{p}\right\} \mid\left\{E_{c}\right\}\right)=\prod_{p=1}^{N P} \frac{1}{\sqrt{2 \pi} \sigma_{p}} \exp \left(-n_{p}^{2} / 2 \sigma_{p}^{2}\right) \text {, }
$$

where $\left\{\sigma_{p}\right\}$ are the standard deviations of each signal measurement.

It is usually convenient to maximize the logarithm of Eq. (2). Thus we arrive at the maximum entropy estimator

$$
-\sum_{c=1}^{N C} E_{c} \ln \left(\frac{E_{c}}{g_{c}}\right)-\frac{\lambda^{2}}{2 C^{2}} \sum_{p=1}^{N P} \frac{n_{p}^{2}}{\sigma_{p}^{2}}=\text { maximum. }
$$

The values $\left\{g_{s}\right\}$ represent the emission values corresponding to the mnst probable object. Equation (3) is maximized subject to the constraints implied by the imaging Eqs. (1) and a constraint on the total emission from the system ${ }^{2,3}$ which arises in the definition of $P^{\text {object. }}$.

$$
I_{0}=\sum_{c=1}^{N C} E_{c}
$$

The constant $\lambda^{2} / C^{2}$, which represents the relative normalization of Pobject and $P^{\text {noise }}$, is used to set the RMS noise in the final solution. Smaller values of $\lambda^{2} / C^{2}$ produce solutions with a larger RMS noise. For $\lambda^{2} / C^{2}=0$ the constraints provided by the imaging equations are relaxed completely and the solution has the profile given by the default image $\left\{g_{c}\right\}$ multiplied by a constant such that the total emission satisfies Eq. (4).

\section{B. Connection to least squares}

If $P^{\text {object }}=$ constant, Eq. (3) reduces to

$$
\sum_{p=1}^{N P} \frac{n_{p}^{2}}{\sigma_{p}^{2}}=\operatorname{minimum}
$$

which. subject to the constraints of the imaging equations. is just a weighted least squares fit. Thus. least squares is the maximum likelihood estimator when all possible objects (including negative ones) are equally probable. 
The method described earlier is an unweighted least squares procedure. but a weighted least squares procedure is easily constructed by dividing each $I_{p}$ by $\sigma_{p}$ and dividing each row $S_{p c}$ by $\sigma_{p}$ before calculating the inverse matrix ${ }^{*}$ M.

\section{Computing the solution}

Lagrange multiplier ${ }^{2,3,8}$ and less efficient but more easily implemented recursive methods have been used to find the maximum of Eq. (3) subject to the constraints from Eqs. (1) and (4). The same techniques have been used for Poisson noise statistics ${ }^{6,10}$ and the conjugate gradient method has been applied for the case of uniform band limited noise with an orthogonal mapping matrix ${ }^{21.12} \mathrm{~S}$.

\section{Lagrange multiplier method}

Application of the Lagrange multiplier method produces a solution with one Lagrange multiplier for each constraint equation. The Lagrange multipliers are then computed using an iterative Newton-Raphson method which requires the inversion of a $N L \times N L$ matrix on each iteration where $N L$ is the number of Lagrange multipliers.

This is quite inefficient for an overdetermined system. There are $N C+N P$ free parameters from $\left\{E_{c}\right\},\left\{n_{p}\right\}$, and $N P+1$ constraints from Eqs. (1) and (4) so there are only $N C-1$ degrees of freedom in the maximization; but the Lagrange multiplier technique requires adjustment of $N L>N P>N C$ Lagrange multipliers.

For our application, where $N P=1024$ and $N C \approx 100 \rightarrow 200$, the method is infeasible on a VAX 8600 .

\section{Back substitution}

As an alternative to the Lagrange multiplier method, we chose to eliminate the constraint Eqs. (1) and (4) from the problem by back substitution. From Eq. (4) we see that the emission from any particular cell can be written 
in terms of all the remaining cells. For notational convenience we pick cell 1.

$$
E_{1}=I_{0}-\sum_{\varepsilon=2}^{N C} E_{e}
$$

The imaging equations can be used to express the noise values $\left\{n_{p}\right\}$ in terms of the measurements $\left\{I_{p}\right\}$ and the cell values $\left\{E_{\varepsilon}\right\}$. So we now have to do an unconstrained maximization of

$$
-E_{1} \ln \left(\frac{E_{1}}{g_{1}}\right)-\sum_{c=2}^{N C} E_{c} \ln \left(\frac{E_{c}}{g_{c}}\right)-\frac{\lambda^{2}}{2 C^{2}} \sum_{p=1}^{N P} \frac{\left(I_{p}-a_{p}\right)^{2}}{\sigma_{p}^{2}}
$$

where $a_{p}$ is the noise free signal

$$
a_{p}=I_{p}-n_{p}=S_{p 1} E_{1}+\sum_{c=2}^{N C} S_{p c} E_{c} .
$$

To obtain the solution, we set the derivatives of expression (6) with respect to the remaining $N C-1$ values $E_{2} \ldots E_{N C}$ equal to zero.

$$
F_{j}=\ln \left(\frac{E_{j} g_{1}}{E_{1} g_{j}}\right)-\frac{\lambda^{2}}{C^{2}} \sum_{p=1}^{N P} \frac{\left(I_{p}-a_{p}\right)}{\sigma_{p}^{2}}\left(S_{p j}-S_{p 1}\right)=0, \quad j=2 \rightarrow N C .
$$

At this point we solve Eqs. (7) iteratively using a Newton-Raphson method ${ }^{3.13}$ in $N C-1$ dimensions. We iterate

$$
\Delta \mathbf{E}=-\mathbf{D}^{-1} \mathbf{F} \quad \text { where } \quad D_{j k}=\frac{\partial F_{j}}{\partial E_{k}^{1}}
$$

and $\triangle \mathrm{E}$ is a vector containing the increments to be applied to $E_{2} \ldots E_{N C}$. The ejements of $\mathbf{D}$ are given by

$$
\frac{\partial F_{j}}{\partial E_{j}}=\frac{I}{E_{1}}+\frac{1}{E_{j}}+\frac{\lambda^{2}}{C^{2}} \sum_{p=1}^{N P} \frac{\left(S_{p j}-S_{p 1}\right)}{\sigma_{p}^{2}}, \quad j=2 \rightarrow \wedge C .
$$

and

$$
\frac{\partial F_{j}}{\partial E_{k}}=\frac{1}{E_{1}}+\frac{\lambda^{2}}{C^{2}} \sum_{p=1}^{N P} \frac{\left(S_{p j}-S_{p 1}\right)\left(S_{p k}-S_{p 1}\right)}{\sigma_{p}^{2}}, \quad k \neq j k, j=2 \rightarrow . V C .
$$

Similar expressions for the case of Poisson noise statistics are given in the appendix. 


\section{Implementation Details}

The summations in Eqs. (9) and (10) are constants for a given system and standard deviation profile so the matrix $\mathbf{D}$ can be quickly loaded if these values are saved prior to beginning the iterations. $\mathbf{D}$ is a symmetric positive definite matrix which can be inverted using Cholesky decomposition. For an overdetermined system the inversion time for this $(N C-1) \times$ $(N C-1)$ matrix is much faster than the $(N P+1) \times(N P+1)$ matrix required in the Lagrange multiplier method. For our case the inversion time is $\approx(1025 / 129)^{3}[$ i.e. $\approx 500$ times] less than the Lagrange multiplier method when using a 130 cell grid. Typically the solution converges in $10 \rightarrow 20$ iterations and takes $30 \rightarrow 60$ seconds on a VAX 8600 . The starting point for the iterations is set as follows:

1. The initial values for the $\left\{E_{c}\right\}$ are obtained from the smoothed least squares method described earlier. Any values of $E_{\varepsilon} \leq 0$ are removed by setting them to $1 \%$ of the average emission.

2. The value for $I_{0}$ is taken from the least squares solution. Since $I_{0}$ is a global property, the least squares value is usually quite accurate.

3. If the value of $\Delta E$ from $E q$. (8) causes one or more of the $E_{c}$ to become

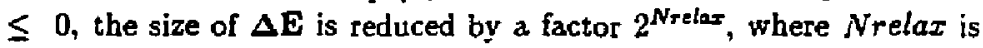
the smallest power of 2 which will make all the $E_{s} \geq 0$.

4. The value $\lambda^{2} / C^{2}$ is initialized and then adjusted periodically during the iterations so that the final solution has a specific total noise requested by the user. The procedure for this is described in the next section.

\section{Adjustment of total noise}

Since it is generally desirable po c . incrol the total amount of noise in the final solution, we introduce a total nin constraint

$$
F_{\text {noise }}=\sum_{P=1}^{N P} n_{:}^{N} ;\left(, \because \sum_{i=1}^{\vee P} \sigma_{p}^{2}\right)-1=0 .
$$


where $C$ specifies the required total noise as a multiple of the value expected from the standard deviations. The value of $\lambda$ is adjusted so that Eq. (11) is satisfied.

When solving for the $\left\{E_{c}\right\}$ in the main iterative loop, $\lambda$ is treated as a constant. If the user picks a value for $\lambda$ from experience with previous solutions and the total noise in the final solution is within acceptable limits. no further adjustment is necessary. However, if we wish to satisfy Eq. (11) exactly, it is necessary to adjust $\lambda$ after obtaining a solution for the $\left\{E_{\mathrm{c}}\right\}$ and then resolve for the $\left\{E_{\mathrm{c}}\right\}$ with the new value of $\lambda$. To determine the adjustment to $\lambda$, we assume that Eqs. (7) are satisfied and that $\lambda$ is a nonlinear function of $\left\{E_{c}\right\}$ which has to be adjusted itezatively using the Newton-Raphson method. The required adjustment to $\lambda$ is given by

$$
\Delta \lambda=-F_{\text {noise }} /\left(\frac{\partial F_{\text {naise }}}{\partial E_{k}} \frac{d E_{k}}{d \lambda}\right), \quad k=2 \rightarrow N C,
$$

where

$$
\frac{\partial F_{\text {noise }}}{\partial E_{k}}=-\frac{2}{C^{2}} \sum_{p=1}^{N P} n_{p}\left(S_{p k}-S_{p 1}\right) / \sum_{p=1}^{N P} \sigma_{p}^{2},
$$

and we can obtain $d E_{k} / d \lambda$ from Eqs. (7)

$$
\frac{d F_{j}}{d \lambda}=\frac{\partial F_{j}}{\partial E_{k}} \frac{d E_{k}}{d \lambda}+F_{j}^{\prime}=0
$$

where

$$
F_{j}^{\prime}=-\frac{2 \lambda}{C^{2}} \sum_{p=1}^{N P} \frac{n_{p}^{2}}{\sigma_{p}^{2}}\left(S_{p j}-S_{p 1}\right) .
$$

The terms $\partial F_{j} / \partial E_{k}$ are just the elernents of $\mathbf{D}$ defined earlier, so

$$
\frac{d E}{d \lambda}=-D^{-1} F^{\prime} .
$$

In practice we do not wait until the $\left\{E_{\mathrm{c}}\right\}$ are fully converged and Eqs. ( 7 ) are satisfied before making an adjustment to $\lambda$. It is normally possible to adjust $\lambda$ after every $3 \rightarrow 4$ iterations of the main loop without disrupting the convergence to a solution. 
To estimate an initial value for $\lambda$ we take the solution from the smootbed least squares method $\left\{E_{c}^{L S}\right\},\left\{n_{p}^{L S}\right\}$ and find the value $\lambda_{0}$ which minimizes $\sum F_{3}^{2}$. This is given by

$$
\lambda_{0}^{2}=C_{0}^{2} \sum_{j=2}^{N C} \alpha_{j} \ln \left(\frac{E_{j}^{L S} g_{1}}{E_{1}^{L S} g_{j}}\right) / \sum_{j=2}^{N C} \alpha_{j}^{2}
$$

where

$$
\alpha_{j}=\sum_{p=1}^{N P} \frac{n_{p}^{L S}}{\sigma_{p}^{2}}\left(S_{p j}-S_{p 1}\right)
$$

and

$$
C_{0}^{2}=\sum_{p=1}^{N P}\left(n_{p}^{L S}\right)^{2} / \sum_{p=1}^{N P} \sigma_{p}^{2} .
$$

The variance of this estimate can be large but it is useful in providing an initial value for $\lambda$ if there are no other estimates available from previously computed solutions under similar conditions.

\section{Additional points}

The algorithm may have difficulty converging if the dynamic range in the values $\left\{g_{c}\right\}$ and $\left\{\sigma_{p}\right\}$ is too large. Care should be taken to ensure that $\max \left(\left\{g_{c}\right\}\right) / \min \left(\left\{g_{c}\right\}\right)$ and $\max \left(\left\{\sigma_{p}\right\}\right) / \min \left(\left\{\sigma_{p}\right\}\right)$ are within the numerical accuracy of the computations. Typically we do not use a dynamic range greater than $10^{3}$. It is also sometimes necessary to compute a solution with a larger total noise than is desired and then continue the computation with a smaller requested noise value using the larger noise solution as a starting point.

\section{Tests of the maximum entropy method}

The algorithm was tested using the method described in section C. For comparison with the least squares method we used the same source and cell grid shown in Figs. 5 and 3 and the same input signals used to produce the least squares result in Fig. 4. For a default image we remcved the asymmetrical component of the original source and took the square root of 
the remaining profile. The default image is shown in Fig. 9. The standard deviations $\sigma_{p}$ were all set equal to the standard deviation of the Gaussian noise generator. The result for $C=0.95$ is shown in Fig. 10. The result for a flat default image is shown in Fig. 11.

Both maximum entropy cases are better than the unsmoothed least squares result. The maximum entropy result with a flat default image is slightly worse on average than the smoothed least squares result, but the accuracy in the central region is basically as good as the maximum entropy result using the better default image. The effect of the maximum entropy procedure is to pull the result towards the default image in the least well-determined regions. For the case of a flat default image, the effect in these regions is roughly equivalent to the smoothing applied to the least squares result.

An interesting example of the stability of the maximum entropy method is demonstrated by the reconstruction in Fig. 12. The default image is the same one used previously, see Fig. 9. The standard deviation used for each pixel was $3.5 \%$ of the signal with an overriding minimum standard deviation of $0.01 \%$ of the maximum signal. The corresponding unsmoothed least squares result is shown in Fig. 13. The original source is shown in Fig. 14. The erroneous structure on the inside edge of the bean is a series of ripples. See the $3 \mathrm{D}$ plot in Fig. 15. The 228 cell reconstruction grid is shown in Fig. 16. The errors in the least squares reconstruction occurred even though there was no noise in the original image supplied to the algorithm.

The main peculiarity of the original source is that it has a large gradient on the inside edge of the bean. The projection of the original source was computed using a slightly higher resolution grid than that used for the reconstruction. This 252 cell grid is shown in Fig. 17. The ripples in the least squares reconstruction can be shown to be due to the fact that the original source contains gradients which cannot be represented on the $22 \$$ cell grid used for the reconstruction. If we use the least squares method to reconstruct the image using the same 252 cell grid used for the projection, we get a perfect result as shown in Fig. 18. The maximum entropy method avoids the rip -1 le error by allowing a larger RMS noise in the solution, $5.25 \%$ vs. $1.13 \%$ for the least squares result. This additional noise reflects the errors introduced by representing the source on the 228 cell grid. 


\section{E. Application to real data}

The default image used for the reconstruction of real data is the set of magnetic flux surfaces produced by a MHD equilibrium fit to the external magnetic measurements of the plasma. The results of the reconstruction for two discharges are shown in figures 15 through 24 . The reconstructions were done using the grid shown in Fig. 16. Figure 19 shows a reconstructed $X$ ray profile and Fig. 20 shows the flux surfaces used for the default image. Figure 21 shows a comparison between the actual camera image and the signal values obtained from the backprojection of the reconstruction.

The plot shows signal vs. camera pixel number for the actual and reconstructed image. The camera pixels are numbered 1 through 1024 and are scanned in 32 vertical columns of 32 pixels starting from the bottom right of the camera image.

Figure 22 shows the reconstructed $\mathrm{X}$-ray profile for another discharge, Fig. 23 shows the default image, and Fig. 24 shows the comparison of actual and reconstructed data.

The RMS noise in these fits is quite high, but the reconstructed images are quite smooth. Examination of the comparison between the backprojected reconstructed image and the actual data seems to indicate that the deviations are caused by some type of systematic error. This could be caused by systematic errors in the camera data or in the mapping function or it could be a consequence of the finite resolution of the reconstruction grid if the source profile contains steep gradients. Further investigation will be necessary to determine the cause and possibly improve the fits.

\section{Conclusions}

The maximum entropy algorithm has been implemented for an overdetermined system in a form which permits the computation of the result in a reasonable time on a VAX 8600 . Comparison with the least squares algorithm shows that the maximum entropy is superior if a good default image can be constructed from additional information about the system. The algorithm permits the external magnetic information from MHD equilibrium fits to be combined with the $\mathrm{X}$-ray pinhole camera data to produce an X-ray emission 
profile which can be used to determine the internal magnetic structure of the plasma.

\section{Acknowledgments}

This work supported by the U.S. DOE fusion postdoctoral program administered by ORAU and U.S. DOE contract DE-ACO2-76-CHO-3073.

\section{Appendix}

Fot the case of Poisson noise statistics, the equations in section III are replaced by the equations below.

$$
P^{\text {noise }}\left(\left\{n_{p}\right\} \mid\left\{E_{c}\right\}\right)=\prod_{p=1}^{v P} \frac{a_{p}^{\left(I_{p} / \Delta I\right)_{e}} e^{-a_{p}}}{\left(I_{p} / \Delta I\right) !}
$$

where $\Delta I$ is the quantum size of the signals $\left\{I_{p}\right\}$. Equation (7) is replaced by

$$
F_{j}=\ln \left(\frac{E_{j} g_{1}}{E_{1} g_{j}}\right)-\frac{\lambda^{2}}{C^{2} \Delta I} \sum_{p=1}^{N P}\left(\frac{I_{p}}{a_{p}}-1\right)\left(S_{p j}-S_{p 1}\right)=0, \quad j=2 \rightarrow N C .
$$

Equations (9) and (10) are replaced by

$$
\frac{\partial F_{j}}{\partial E_{j}}=\frac{1}{E_{1}}+\frac{1}{E_{j}}+\frac{\lambda^{2}}{C^{2} \Delta I} \sum_{p=1}^{X P} \frac{I_{p}}{i_{p}^{2}}\left(S_{p j}-S_{p 1}\right)^{2}, \quad j=2 \rightarrow \wedge C
$$

and

$$
\frac{\partial F_{j}}{\partial E_{k}}=\frac{1}{E_{1}}+\frac{\lambda^{2}}{C^{2} \Delta I} \sum_{p=1}^{V P} \frac{I_{p}}{a_{p}^{2}}\left(S_{p j}-\ddots_{1} \therefore_{p \alpha}-S_{p 1}\right), \quad k \neq j k, j=2 \rightarrow . V C .
$$

Equation (11) remains the same ".u.n' that $\sum \sigma_{p}^{2}$ is replaced by a suitable value for the expected total now.. $l: \ldots, \ldots$ tion (12) is replaced with

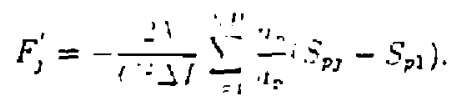


Equation (13) remains the same with $\alpha_{j}$ given by

$$
\alpha_{j}=\frac{1}{\Delta I} \sum_{p=1}^{N P}\left(\frac{I_{p}}{a_{p}}-1\right)\left(S_{p j}-S_{p 1}\right) .
$$




\section{References}

${ }^{1}$ R. J. Fonck, M. Reusch, K. P. Jaehnig, R. Hulse, and P. Roney, "Soft X-ray imaging system for measurement of noncircular tokamak plasmas," SPIE. 691, X-ray imaging II. 111 (1986).

${ }^{2}$ B. Roy Frieden, "Restoring with Maximum Likelihood and Maximum Entropy," J. Opt. Soc. Am. 62. 511 (1972).

${ }^{3}$ A. Holland and G. A. Navratil. "Tomographic analysis of the evolution of plasma cross sections." Rev. Sci. Instrum. 57, 1557 (1986).

'E. T. Powell, Ph.D. thesis Princeton U'niversity, 1990.

${ }^{5} \mathrm{R}$. Decoste, "X-ray tomography on plasmas with arbitrary cross sections and limited access," Rev. Sci. Instrum. 56, 807 (1985).

${ }^{6}$ B. Roy Frieden, "Unified theory for estimating frequency-of-occurrence laws and optical objects," J. Opt. Soc. Am. 73, 927 (1983).

'W. H. Press, B. P. Flannery, S. A. Teukolsky, W. T. Vettering, Vumerical Recipes, p. 509 ft (Cambridge University Press, New York, 1986).

${ }^{8}$ B. Roy Frieden, D. C. Wells, "Restoring with maximum entropy. III. Poisson sources and backgrounds." J. Opt. Soc. Am. 68, 93 (1978).

${ }^{9}$ E. S. Meinel, "Origins of linear and nonlinear recursive restoration algorithms," J. Opt. Soc. Am. A 3. is7 (1986).

${ }^{10} \mathrm{E}$. S. Meinel, "Maximum-entropy image restoration: Lagrange and recursive techniques." J. Opt. Suc. An. A 5, 25 (198S).

"L. Barrodale, C. A. Zala. and R. F. Mackinnon, "Image processing by a maximum entropy procedure incorporating frequency domain bounds and prior knowledge," in Conference Proceedings, IEEE Pacific Rim Conference on Conmunications. Computers and Signal Processing, June 4-j.j. 1987. Victoria. B.C. (IEEE. New York, 1987).

12R. F. Machinnon. "Minimum cross-entropy noise reduction in images." $J$. Opt. Soc. Am. A 6. 339 (1989). 
${ }^{13}$ W. H. Press, B. P. Flannery, S. A. Teukolsky, W. T. Vettering, Vumerical Recipes. p. $254 \mathrm{ff}$ (Cambridge University Press, New York, 1986). 


\section{Figures}

FIG. 1. Pinhole camera's view of the plasma.

FIG. 2. Function showing relative contribution of each point in the source to the camera image.

FIG. 3. 130 cell grid used in reconstructions.

FIG. 4. Unsmouthed least squares reconstruction of source in Fig. $5 . \Delta_{r m s}=$ $21.4 \%$.

FIG. 5. Original source for tests.

FIG. 6. Least squares reconstruction with one smoothing pass. $\lambda_{r m s}=$ $16.6 \%$.

FIG. 7.76 cell grid used in reconstructions.

FIG. 8. Unsmootined least squares teconstruction using 76 cell grid. $\Delta_{r m s}=$ $12.9 \%$.

FIG. 9. Default image used for maximum entropy reconstruction tests. $\Delta_{r m s}=$ $42.7 \%$.

FIG. 10. Maximum entropy reconstruction using bean-shaped default image.

$$
\nu_{r m s}=10.8 \% \text {. }
$$

FIG. 11. Maximum entropy reconstruction using flat default image. $\Delta_{r m s}=$ $18.1 \%$.

FIG. 12. Maximum entropy reconstruction of source in Fig. 14 using default image in Fig. 9 and 228 cell grid in Fig. 16. $\Delta_{r m s}=10 \%$.

FIG. 13. Unsmoothed least squares reconstruction of source in Fig. 1t using 228 cell grid. $\Delta_{r m s}=20.7 \%$.

FIG. 14. Source used to demonstrate errors caused by large gradients.

FIG. 15. 3D plot of result in Fig. 13. 
FIG. 16. 228 cell grid used for reconstruction of source in Fig. 14.

FIG. 17. 252 cell grid used to specify source in Fig. 14.

F[G. 18. Linsmoothed least squares reconstruction of source in Fig. 14 using 252 cell grid. $\Delta_{r m s}=0 \%$.

FIG. 19. Maximum entropy reconstruction of a real plasma source using the default image in Fig. 20. $\Delta_{r m s}=16.9 \%$.

FIG. 20. Equilibrium magnetic flux surfaces useci as a default image for the reconstruction in Fig. 19.

FIG. 21. Comparison of the signals on each pixel in the camera image produced by the real data and the backprojection of the reconstructed $\mathrm{X}$-tay profile for the reconstruction in Fig. 19.

FIG. 22. Maximum entropy reconstruction of another discharge using the default image in Fig. 23. $\Delta_{r m s}=27.7 \%$.

FIG. 23. Equilibrium magnetic flux surfaces used as a default image for the reconstruction in Fig. 22.

FIG. 24. Comparison of the signals on each pixel in the camera image produced by the real data and the backprojection of the reconstructed X-ray profile for the reconstruction is. Fig. 22. 


\section{PBX-M SOFT X-RAY CAMERA.}

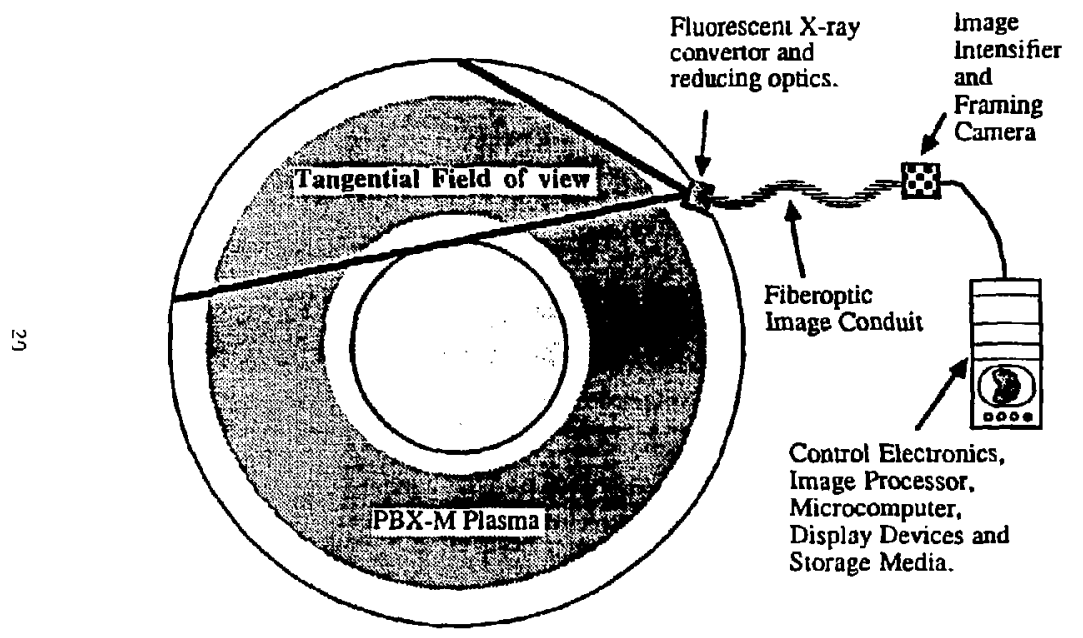


Detector conf iguration for datafile MFOP.R

1024 active channels

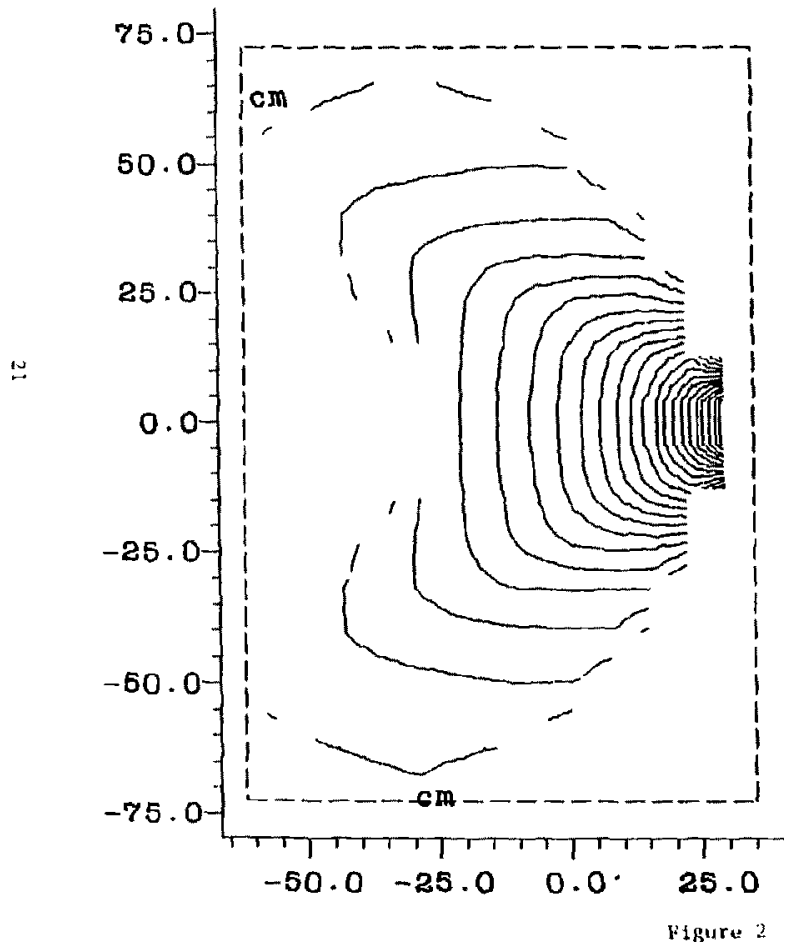

Welght flle name MFOP. $R$

Matrix origin

$R=-80.28 \quad \mathrm{~cm}$

$\mathrm{Z}=-67.97 \quad \mathrm{~cm}$

Cell size

$R=7.438 \quad \mathrm{~cm}$

$\mathrm{Z}=9.063 \mathrm{~cm}$

152 Normal cells

o Odd cells

152 Matrix cells

Weight contour levels Level $1=4.295 \mathrm{E}-05$ Increment $=2.075 \mathrm{E}-04$ Welght range M1nimum $=7.266 E-13$ Maximum $=8.760 E-06$ 
Detector conilguration for dataflle MS3P newfmt.R

1024 actlve channels 0 deleted channels

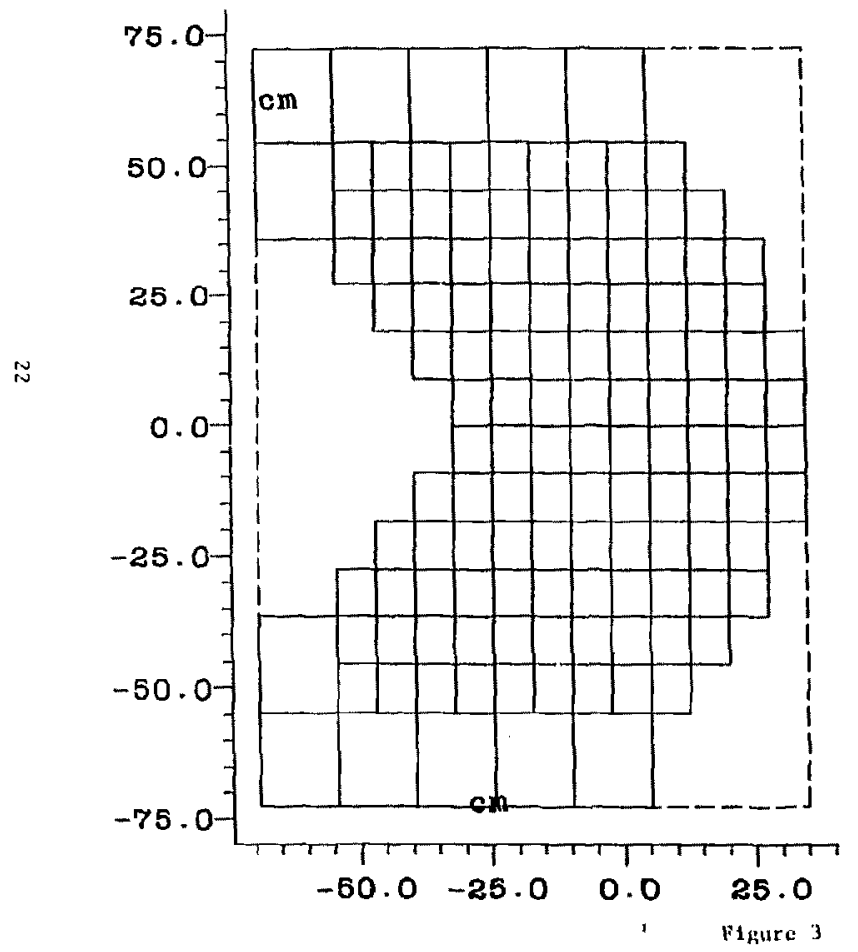

Welght file name MS3P_newfit.R

Matrix origin

$R=-80.28 \quad \mathrm{~cm}$

$\mathrm{z}=-67.97 \quad \mathrm{~cm}$

Cell size

$\begin{array}{ll}\mathrm{R}=7.438 & \mathrm{~cm} \\ \mathrm{Z}=9.063 & \mathrm{~cm}\end{array}$

130 Normal cells

0 Odd cells

-1 Matrix cells

Plgure 3 


\section{4 active channels}
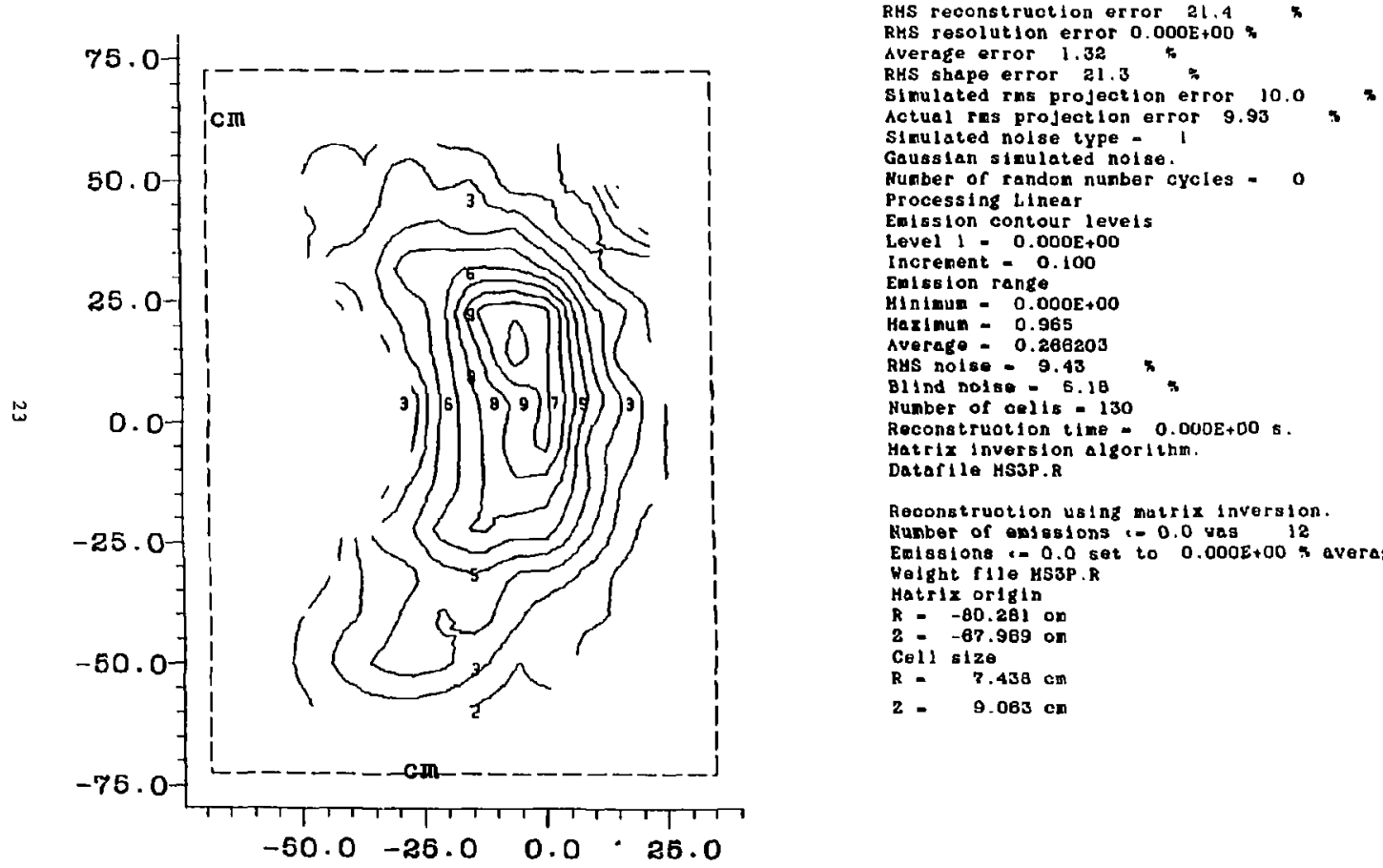

Reconstruotion using matrix inversion. kumber of esssisoss $=0.0$ yes is Emisgions c 0.0 set to $0.000 E+00$ t average.

Helght flle HS3P. R

Hatrix origin

R $=-80.281$ od

$2=-67.989$ on

Gell size

$R=\quad 7.438 \mathrm{~cm}$

z $=9.063 \mathrm{~cm}$ 


\section{4 active channels}

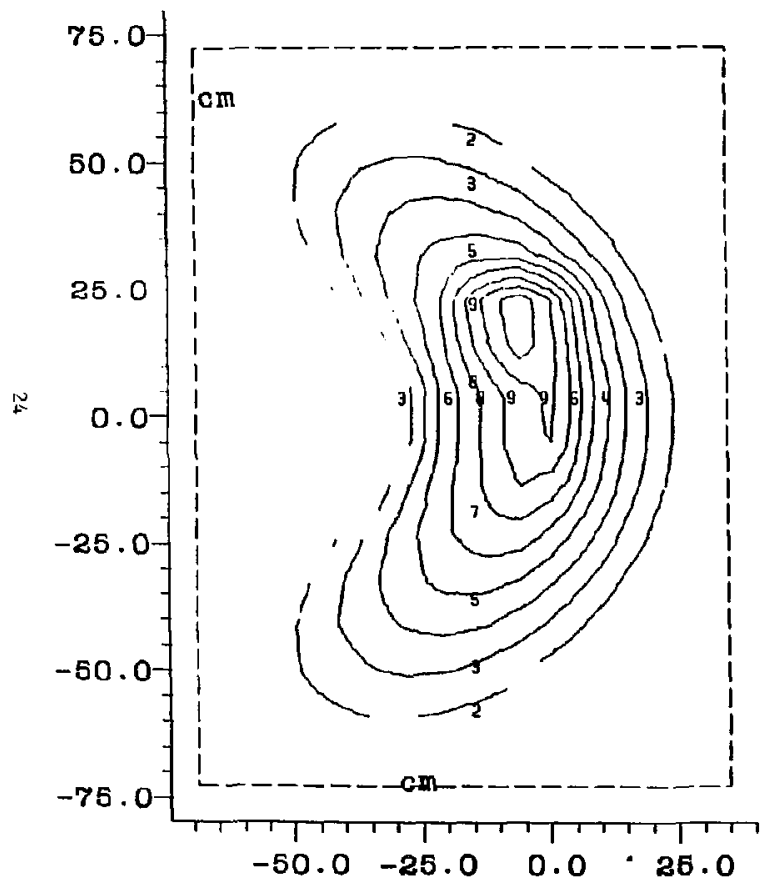

RHS reconstruction error $0.000 E+00$ *

RHS resalution error $0.000 E+00$.

average erfor 1.32

RHS shape error 16.6 \%

Processing Linear

Entssion contour levels

Level I - 0.000E+00

Inorenent - 0.100

En1ssion rango

HISI nun - I.382E-04

Haximun - 0.977

Average - 0.266203

Dataflle MS3P.R

Reconstruction using natrix inversion. Nunber or enissions $<-0.0$ vas 12

Emissions -0.0 set to $0.000 E+00$ average.

number of blinear smoothing passes = 1

Welght tilo USJP, R

Matrix orlgin

R - -80.281 on

$2=-67.969$ on

Cell $512 \theta$

R - 7.438 on

Z $=9.083 \mathrm{~cm}$ 


\section{4 active channels}

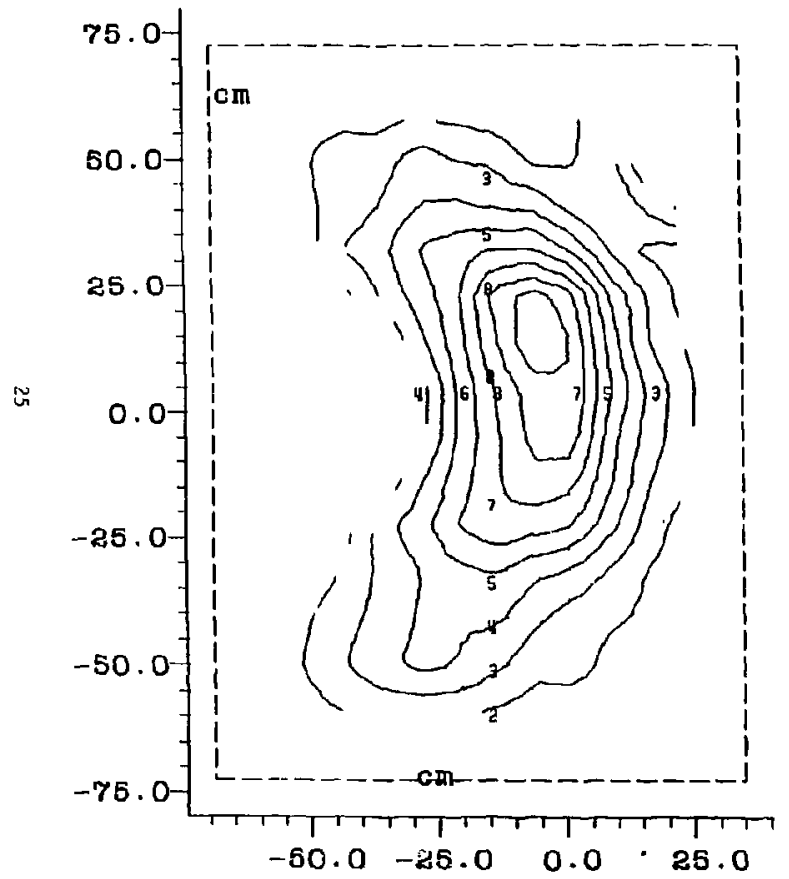

RHS reoonetruction error 16.6
rHS resolution error $0.000 \mathrm{E}+00$

Average error 1.32
RHS siape error 10.6

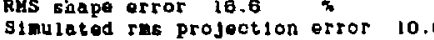

Actual Ins projection error 9.93

Sinuleted nolse type = 1

Gaussian simuleted nolse.

Number of random number cycles - 0

Processing linear

Enis lon contour lovels

Leve 1 - D.000E +00

Inorenant $=0.100$

Eolselon range

Minitua - 0,000E $\$ 00$

Hexicun $=0.894$

Averege $=0.266203$

RHS nolse $=10.4$

Blind nolse $=$ a.30

Humber of 0011E - 130

Reoorstruetion tine $=0,000 \mathrm{z}+00 \mathrm{~s}$.

Hatrix Inversion algorithm.

Detaflio MS3P.

Reoonstruotion using natrix inversion.

Kumber of oniselons i- 0.0 was 12

Emiesions $=0.0$ set $20 \quad 0.000$ to 00 averago

Nunber of bllineas smoothing parses - 1

Weight rile asis.

Hatrix orlgin

R- $-80.281 \mathrm{~cm}$

$z=.67 .969 \mathrm{~cm}$

Cell 5120

$R=7.438$ am

$z=9.063$ un 


\section{Detector configuration for dataflle MSEP.R}

1024 active channels

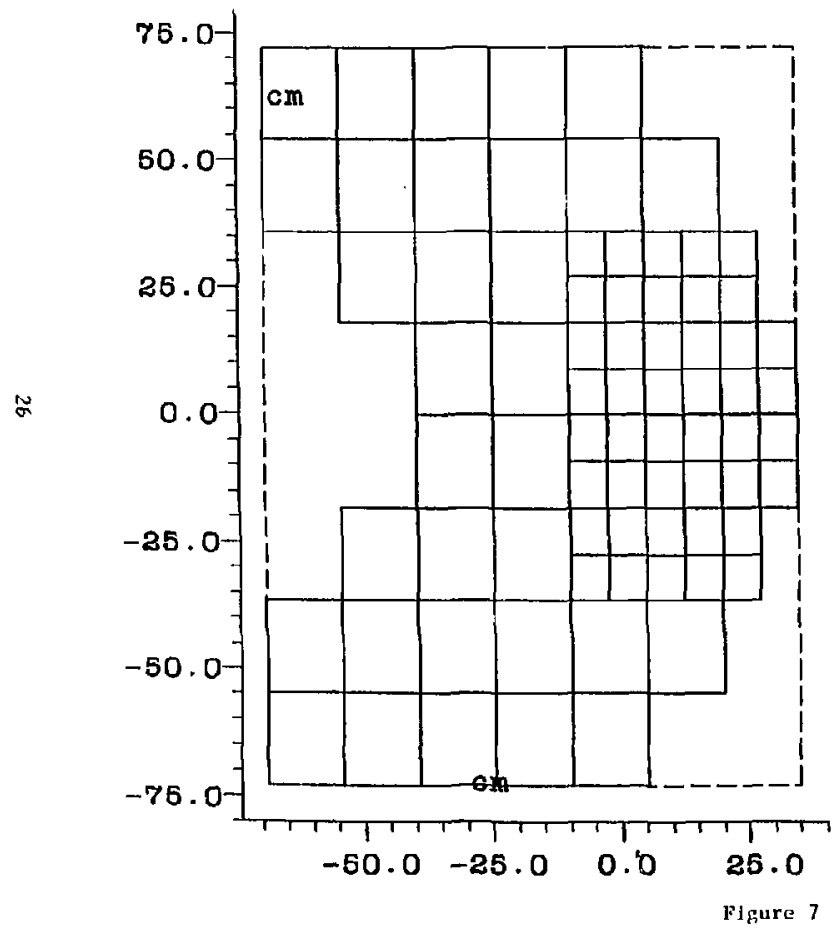

Welght file name MS2P.R

Matrix origin

$R=-80.28 \quad \mathrm{~cm}$

$\mathrm{Z}=-68.38 \quad \mathrm{~cm}$

Cell size

$\mathrm{R}=7.438 \quad \mathrm{~cm}$

$\mathrm{Z}=9.063 \mathrm{~cm}$

76 Normal cells

o Odd cells

-l Matrlx cells 


\section{4 active channels}

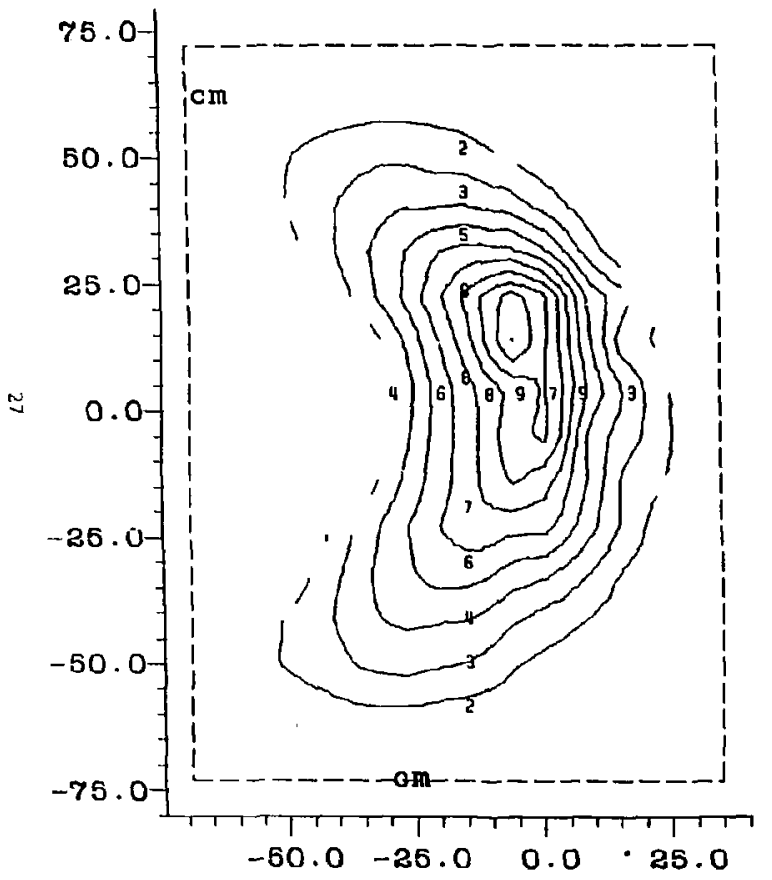

RHS reconstruotion error 12.9

RHS resolution error $0.000 \mathrm{E}+00$,

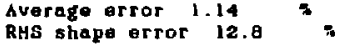

RHS shape error 12.8

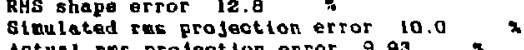

Actual rms projeation error $9 . \theta 3$

Sinulated notse type -

Gausian sivulatad nolse.

Number of randoz number ayoles - D

Prooessing linear

Emission contour levels

Level l-0.00DE+CO

increont - 0.100

Ealsston range

HInImue - 0.000E+00

Haximus $=1.01$

Averaga -0.287413

RHS notse $=10.7$

Blind nolve $=4.06$

Nunber of cel18 $=76$

Reoonetruction tine - 0.00aE+00 o

Hatrlx Inversion algorithn.

Dater 10 HS3P. R

Reoongtruation uglng matrix inversion. Nunber of entsolone $<0,0$ vas 8

Eniselone a 0.0 set to $0.000 \mathrm{t}+00$ average. Nelgbe f110 HS2P.F

Metsis origin

A $=-80.281$ on

$2=-88.375$ on

Cell size

$R=7.438 \mathrm{om}$

$2-9.083 \mathrm{om}$

Fipure 8 


\section{4 actlve channels}

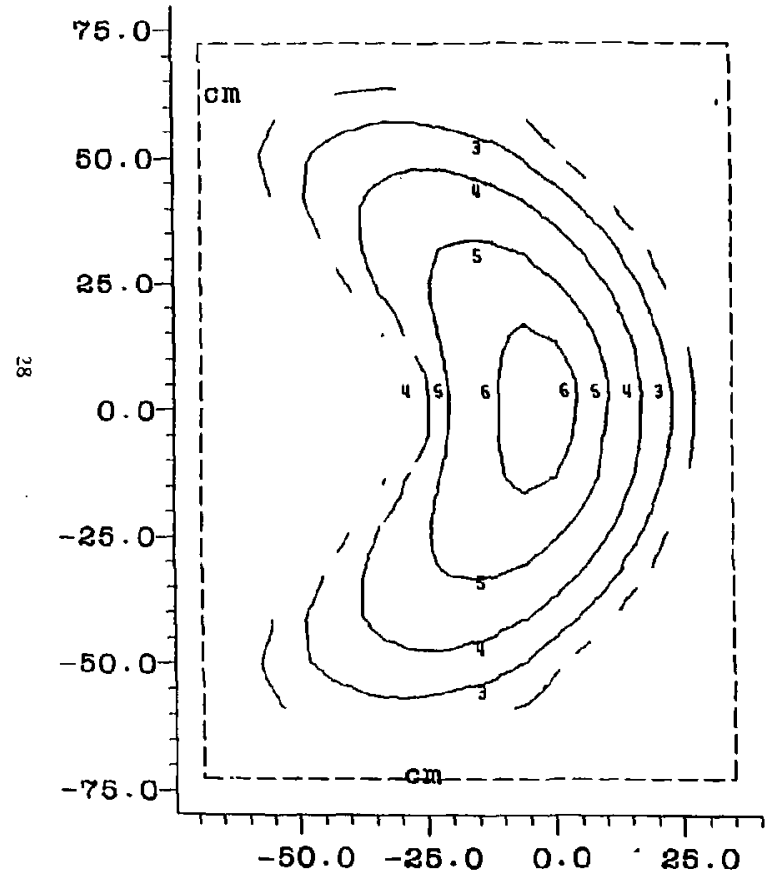

RHS reconstruotion error 42.7

RHS resolution error $0.000 E+00$.

Average error $0.000 \mathrm{E}+00$ :

Rhs shape error 40.8

processing linaur

Enlesion contour levele

Level l - 0.000E+00

Inorement $=0.100$

Eniseton rango

HInImua - 1.085E-03

Haxivun = 0.555

Average - 0.26269 l

Datarilo MS3P.R

Default Image file 3HF3P.D

velfbt r110 HSJP.R

Matrlx orlgin

$R=-80.281$ on

Z $=-67.969$ ov

Cel1 120

R $=7.438$ or

2. 9.063 on 


\section{4 actlve channels}

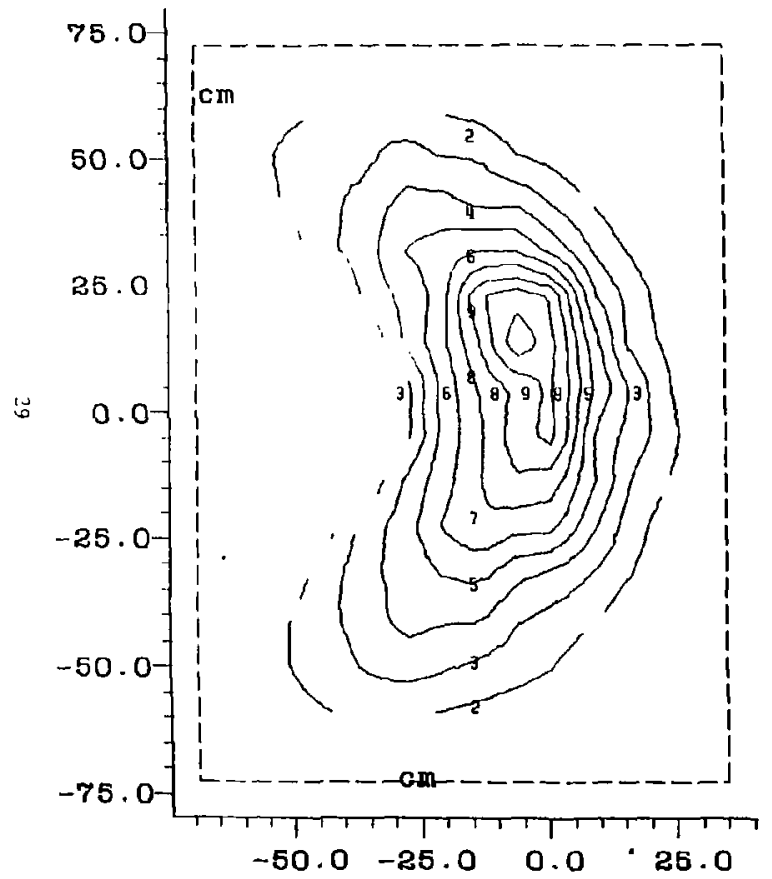

RHS reconstruotion error 10.8

RHS resolution error 0 OOOE+OO =

Average error 1.32

RHS shape error 10.8 \%

Simulated ras projeotion error 10.0 Actual rms projection errar 9.93 simulated nolse type - 1

Gaussian siaulated noise.

Number of random number cycles - 0

Processing linear

Enission contour levels

Level $1=0.000 E+00$

Increment $=0.100$

Enission range

HinImun = 3.799E-04

Maximun $=0.980$

Average - 0.266203

Gaussian notse statistics.

Natse level $=0.950$

Shar pness - $1.143 E+09$

hus sta. dev. $=9.99$

std. dev. type - 0

RHS notse $=9.49$

Blind nolse = 5.11

Number of oel1s - 130

Number of lterations - B

aeconstruation time = 41 .

Fast HE algortihn.

Dazarl 10 HSJP.R

Derault Inage file 3HF3P.D

Welght file HSJP, R

Hatrix origin

R - -80.281 on

2. $-67.969 \mathrm{om}$

Coll $812 \theta$

R - 7.43B cm

2 - 9.083 om 
Reconstructed numerical phantom. File:- 3MS3P.E

\section{4 active channels}

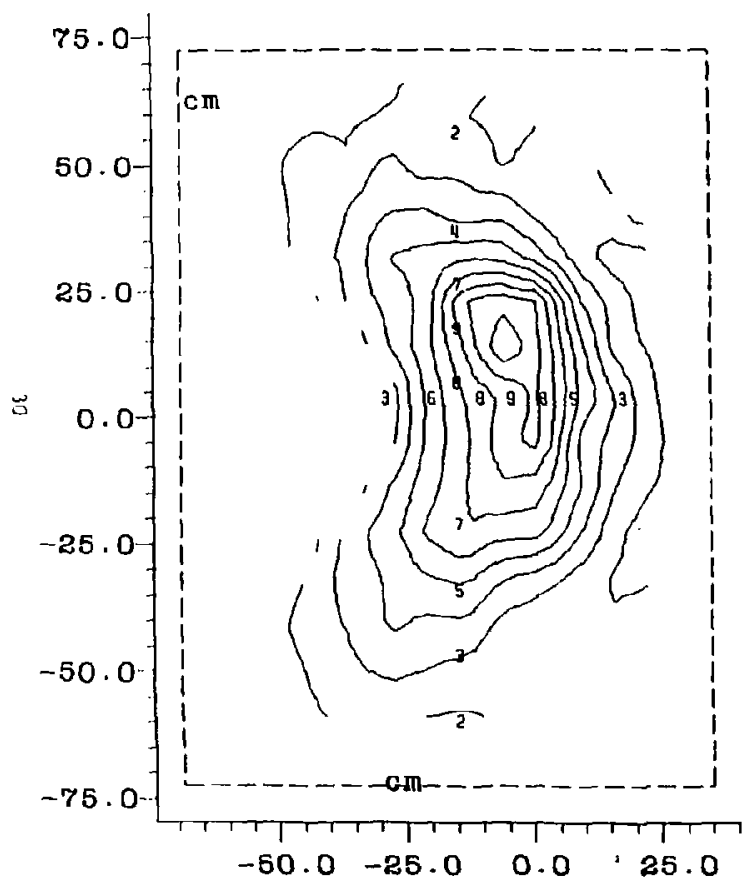

RMS reconetruotion error 18.1

RHS resolulion error 0.000E,00\%

Average error $1.32=$

RHS shepe error 18.1 .

Sinulated ras projeotion error 10.0

Aotusl ras projection error 9.9

Sinulated nolse typo - 1

Gaussian sinulated noise.

Number of randon number cyoles - 0

Processing Linear

Emisston contour levels

bevel 1 - 0.000E +00

Increment - 0.100

Emisston rango

HInimun - 7.557E. Os

Haxigun - 0.98?

Average - 0.266203

Gausian nolse stetistiog.

Nol 60 lovel $=0.950$

Sharpness - $3.828 E+09$

RHS sld. dov. $=9.99$

sta. dev. typo $=0$

RHS nolse $=9.50$

Bilnd nolse - 5.10

Humber of cells $=130$

Number of iterotions - 9

Reconstruction time - 35.

Fast HE algortthm.

Dataf 110 HS3P.R

Default lage is flat

Wedght rlle HSBP.R

Hatrix origin

R $=-80.281 \mathrm{~cm}$

$Z=-87.969 \mathrm{~cm}$

Cel1 6120

R - 7.438 om

2 - 9.083 on 


\section{4 active channels}

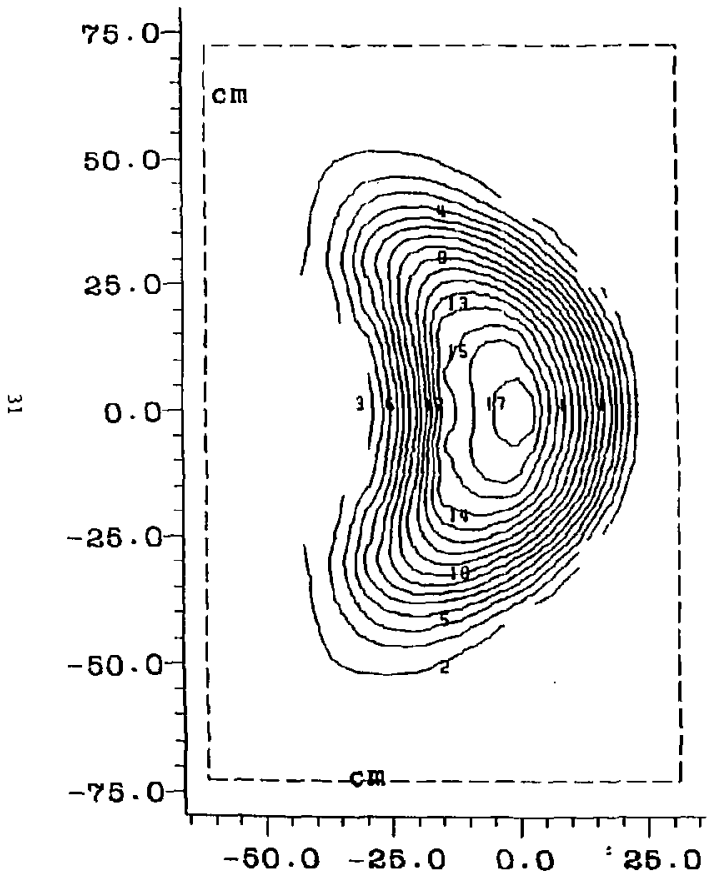

RHS reconstruation error 10.0

RMS resolution error 0.000E+00*

Averege error 0.528 7.

RHS sbape errot 9.55 .

Sinulated rms projootion error $0.000 \mathrm{t}+00 \mathrm{~h}$ Aclual ras projeozion error 0.ODOE +00 n Simulated notige typo - 0

Unifora slaulated nolse.

Number of random number oyoles - 0 Processing Linear

Entigian oontour levels

Level $1=0.000$ + 00

Increment - 15.0

Enision range

HInInun $-3.451 E-12$

Haximun - 253

Average - 83.4901

Geussian nalse statistios.

Holse level $=0.350$

Sharpness - B.710E+06

RHS sed. dev. - 15.0

std. dov, type $=1$

5td. dou. aIn $=2.000$-05

Std. dev. aln = 4.236E-02 of max signel

std dev. - 0.000E+00 of slignel

RHS nolse $=5.25$

Blind nolse $=0.000 E+00 x$

Number of colls - 228

Number of 1teralsons - 62

Reoontiruction $1100-63.0$

Pagt HE algorithn.

Dotef 11 HF 4 , R

Default Inage file 3HF 4F, D

Weight flle GFaP.R

Hatria origin

$R=-82.141$ on

$2=-70.2340$

Coll 8120

R $=3.718 \mathrm{om}$

$2-4.531$ on

Finure 12 


\section{4 active channels}

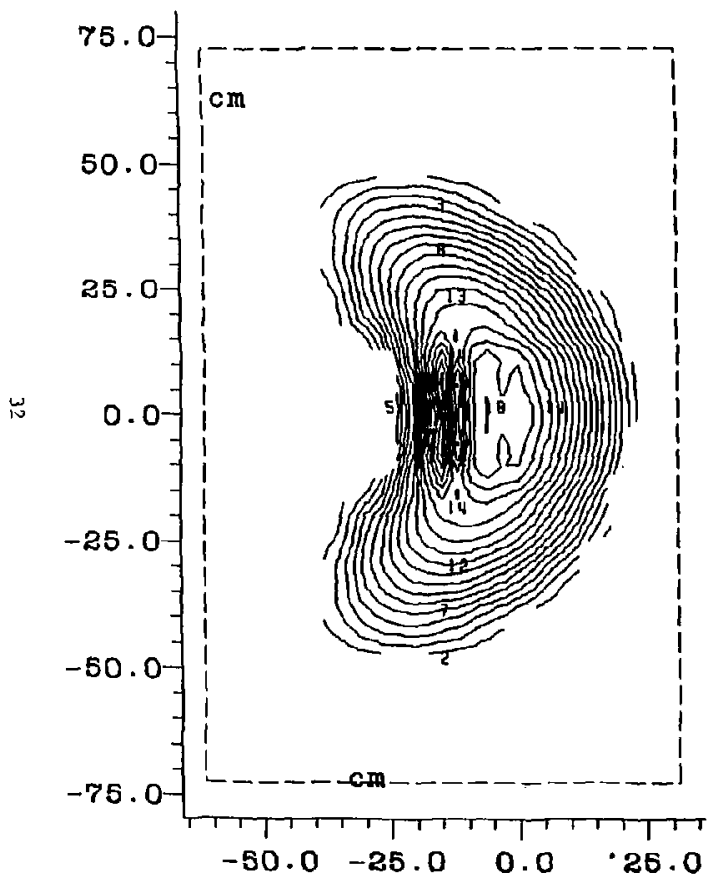

RHS reoonstruotion error 20.7

RHS resolution error $0.000 E+00 \%$

Average error 0.520

AHs thope arror 20.4

Ginulated res projection error 0.0005+00\%

Actual ras prajeatian errar $0.000 E+00$ *

Sinulated nolso typo -

Unirorn sinulated noise

Number of randor number cycles = 0

Prooessing Linear

Enisiton oontour levels

Level $1=0.000 E+00$

Increment - 15.0

EnIseion range

Hintaun = 0.00DE+DO

Haxtmun - 295 .

Average = 83.4901

RHS nolse- 1.13

Bilnd nolse $=0.000 E+00$ \%

Humber of colls -228

Reconstruetson tige - 23.9 E.

Matriz inversion aldorithm.

Datafilo HFAP.R

Reoonstruction using netrix inversion.

Number of emlestans $<0.0$ yas 52

En1salons -0.0 get to 0.0DOE+OD * averago

Woight f110 HFAP.R

Hoterla or $18 ! n$

$R=-82.141 \mathrm{on}$

$z=-70.234$ on

Gell slze

R. $3.719 \mathrm{~cm}$

$2=4.531 \mathrm{~cm}$ 


\section{4 active channels}
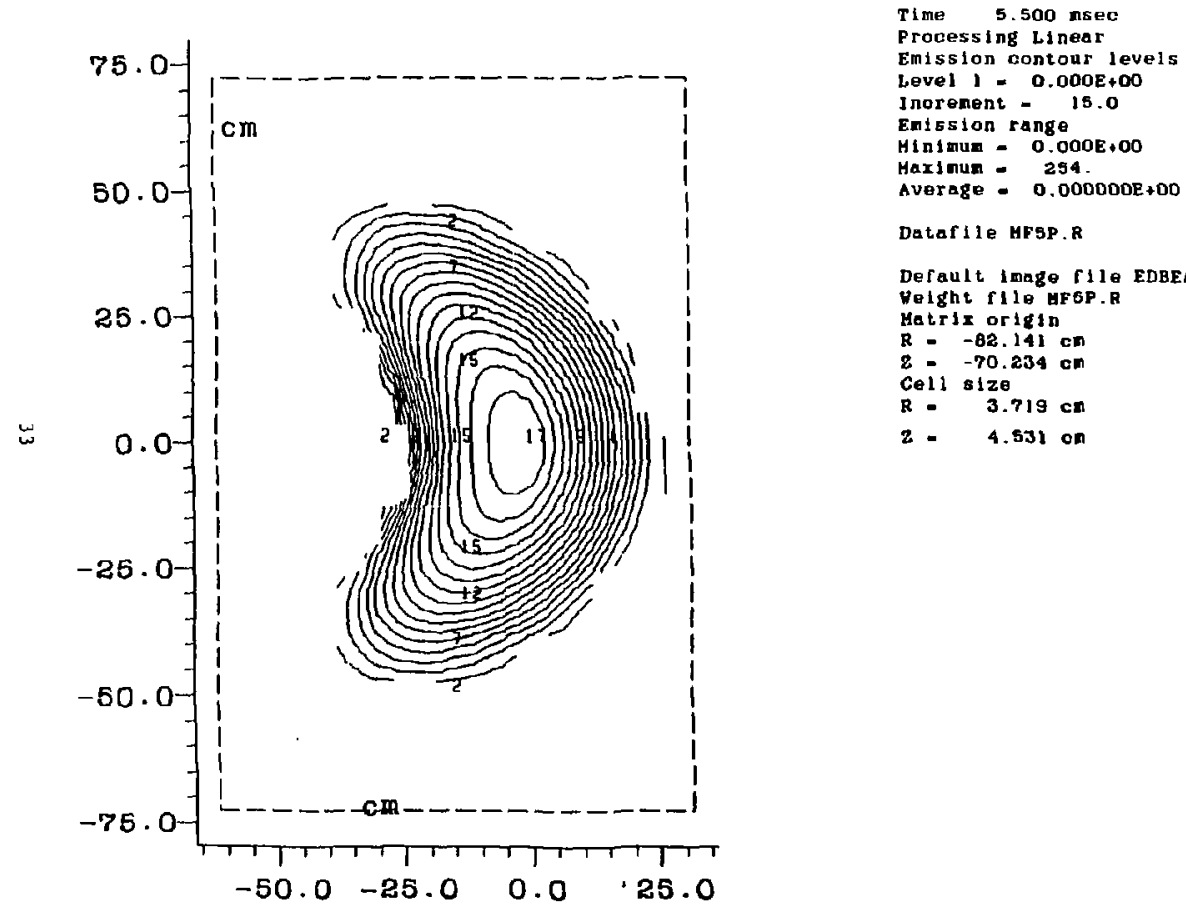

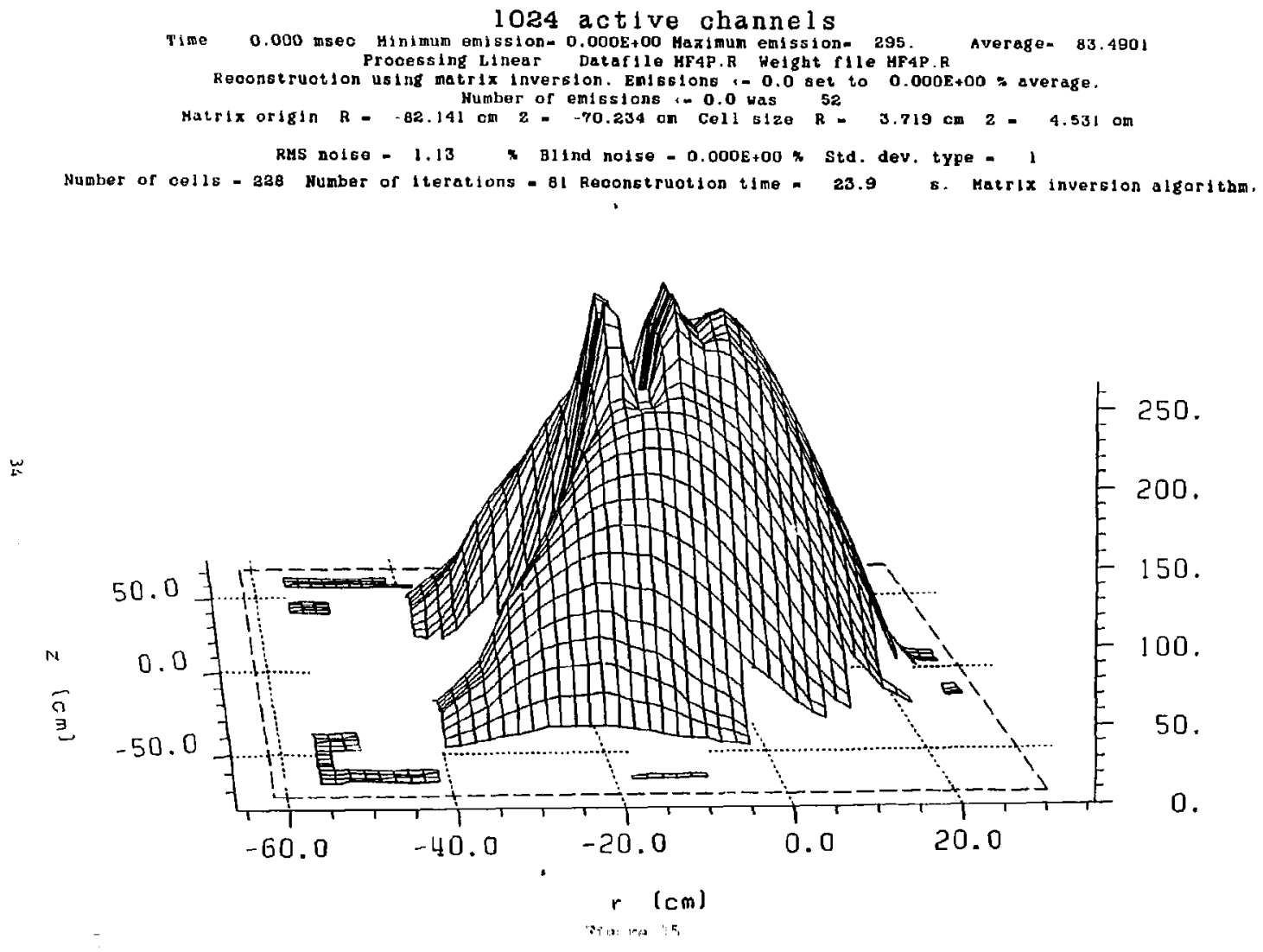
Detector configuration for dataflle MF4P.R
1024 active channels
0 deleted channels

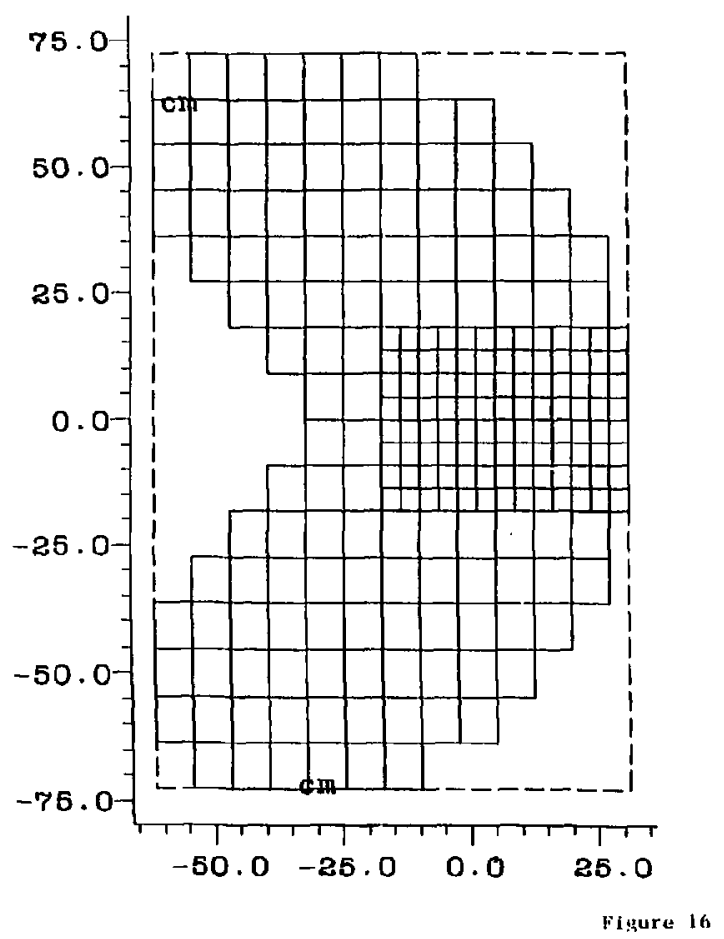

Welght file name MF4P.R

Matrix origin

$R=-82.14$

$\mathrm{cm}$

$\mathrm{Z}=-70.23$

$\mathrm{cm}$

Cell size

$R=3.719 \quad \mathrm{~cm}$
$\mathrm{Z}=4.631 \mathrm{~cm}$
228 Normal cells
0 Odd cells
- I Matrlx cel1s


Detector configuration for datafile MF5P.R

1024 active channels

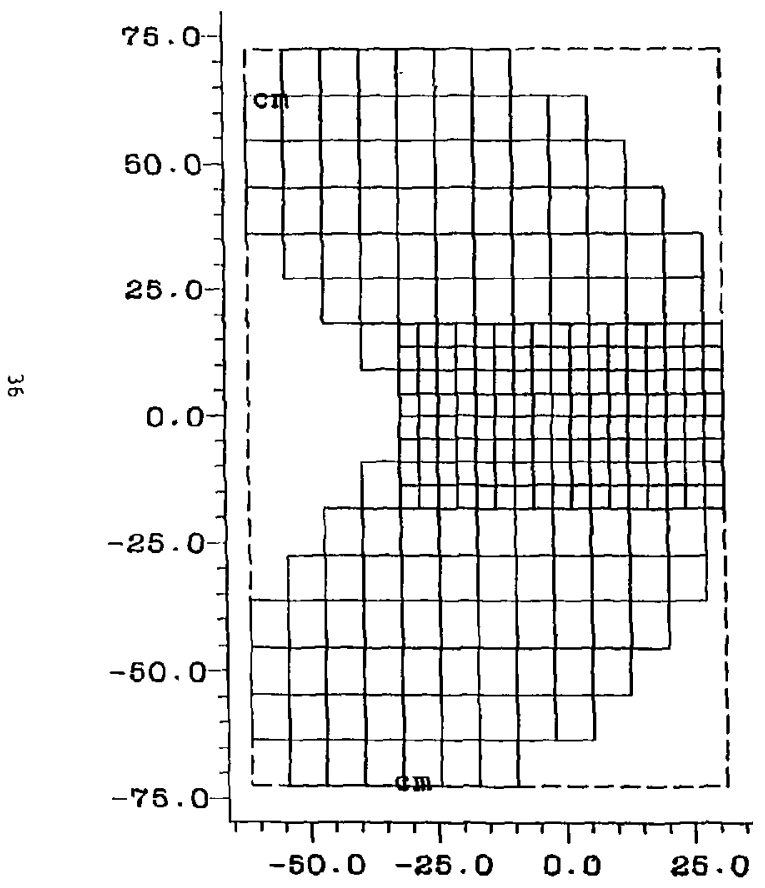

Weight flle name MF5P.R

Matrix origin

$\mathrm{R}=-82.14 \quad \mathrm{~cm}$

$\mathrm{z}=-70.23 \quad \mathrm{~cm}$

Cell slze

$\mathrm{R}=3.719 \mathrm{~cm}$

$\mathrm{Z}=4.531 \quad \mathrm{~cm}$

252 Normal cells

G Odd cells

-1 Matrix cells 


\section{4 active channels}

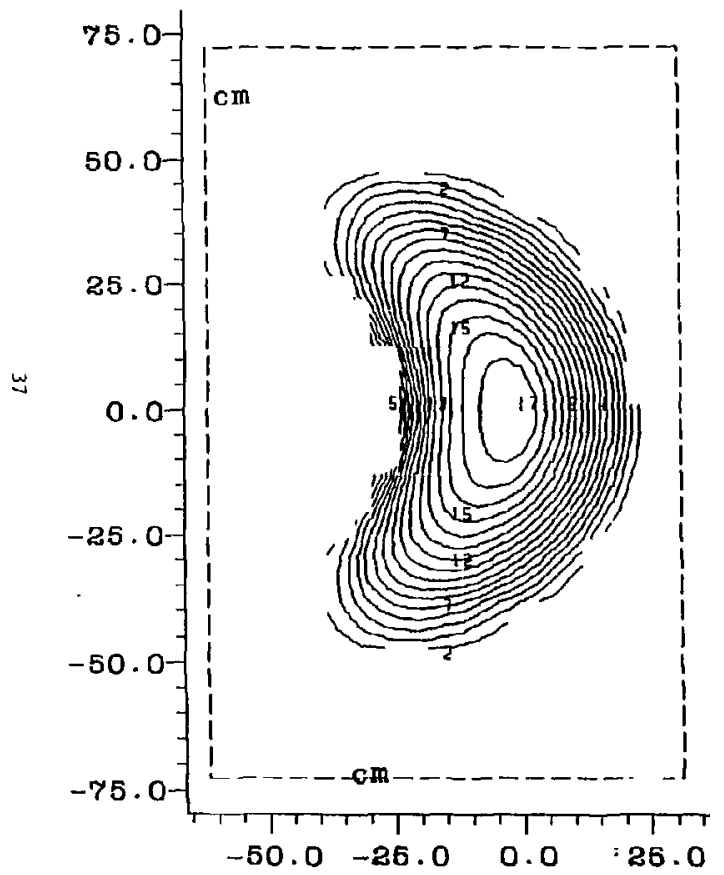

RHS reoonstruetion error $0.000 E+00 *$

RHS resolueion error O.DOOE +00 ?

Average error $7.163 E-05$ s

RHS obape error O.DOOE +00 *

simulated ras projeotion erfor $0.000 E+00$ t

hotual ras projection error $0.000 E+00 *$

Simulated nole type - D

Uni rorm gimulated nolso.

Number of rendor number cyoles = 0

Prooessing IInear

Enisston contour levels

Level I - 0,000E+00

Inorewent $=16.0$

Enises on rang

HInimue - 0.S100E+00

Hax1zun - is4.

Average - 82.3024

RHS no1 $80=1.682 E-04 \times$

Blind nolse $=0.000 \mathrm{E}+00$

Number of $00118=252$

Reoonseruotion tine = O.000E+00 s

Hatrix inverston algoritbn.

Deterlle HF4P.R

Reconstruotion using matrix inversion.

Number of entesions :- 0.0 us

Eulsgiona a o o set to 0.000E+00 average.

Welght file HFSPDP.R

Matrix origln

R $=-82.141 \mathrm{~cm}$

$2=-70.234 \mathrm{~cm}$

Gell stze

$R=3.719 \mathrm{~cm}$

$2=4.531 \mathrm{~cm}$ 
PBX Soft X-ray Emission Cross-section:

\section{4 active channels}

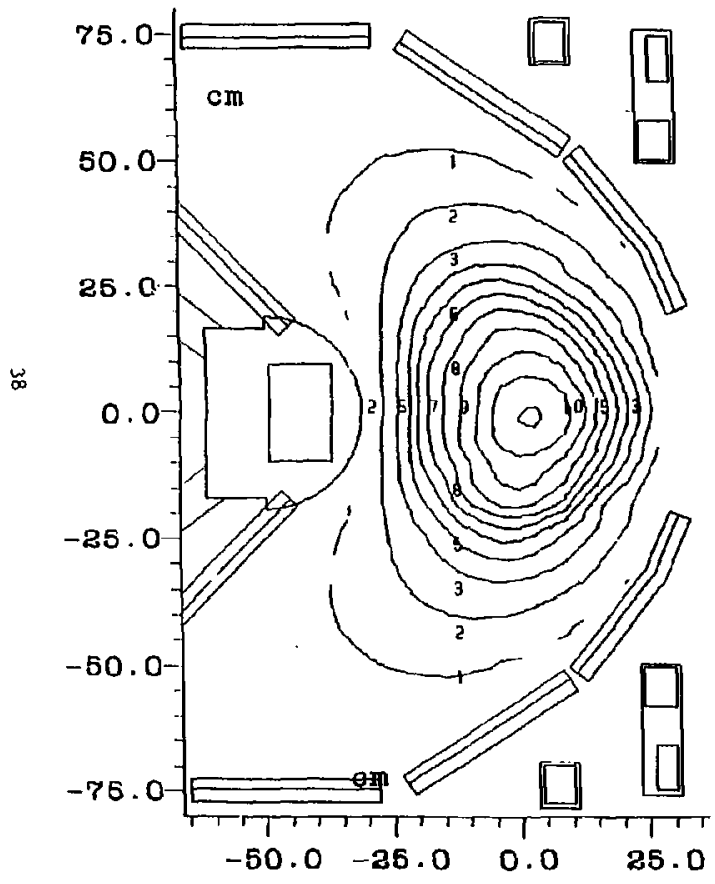

Tine 430.000 nseo

Proceselag Lincar

EnIbsion contour levels

Level $1=1.000 E+05$

Inorement $=4.000 E+05$

Emiscton range

Hinimun - giz.

Haximun $-4.212 E+06$

Average = 1.246s75E+06

Gausian nolso statistios.

NolBe lovel $=1.00$

Sharpnese - 26.0

RHS Sed. dev, $=4.5$

sla dev. eype

RHS nolse = 18.9

Blind notse -4.61

Nunber of col1s-218

Huber of lterations - 12

Reconctruction tias= 12.0

FASt HE algoritha.

Delaflle CHTR_PERP.LATE

Default image flle w: 269084_asoporo,D Volght J110 HFAR.R

Hatrix origit

$\mathrm{R}=-67.000 \mathrm{~cm}$

$2=86.000$ on

Cell size

$\mathrm{R}=\quad$ 4.000 $\mathrm{ck}$

Z $=4.000 \mathrm{~cm}$ 


\section{4 active channels}
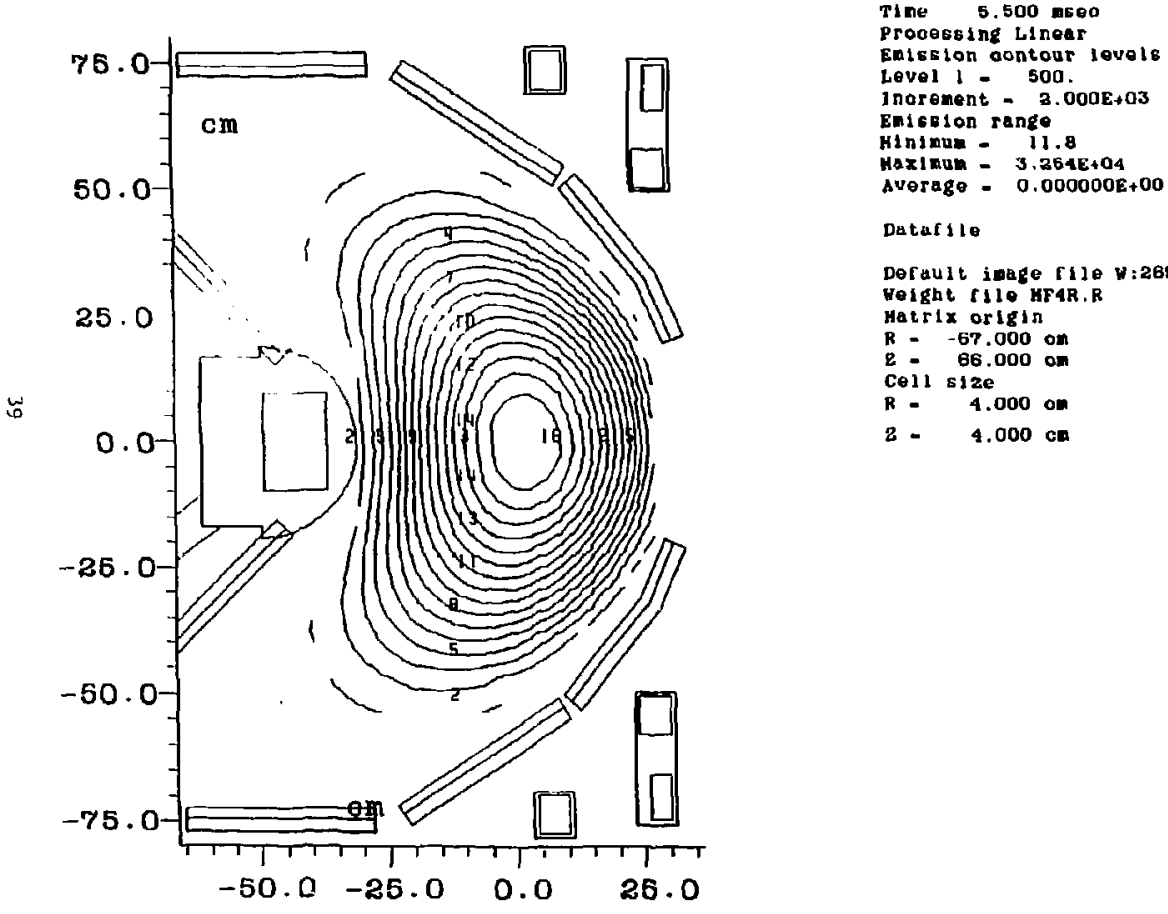


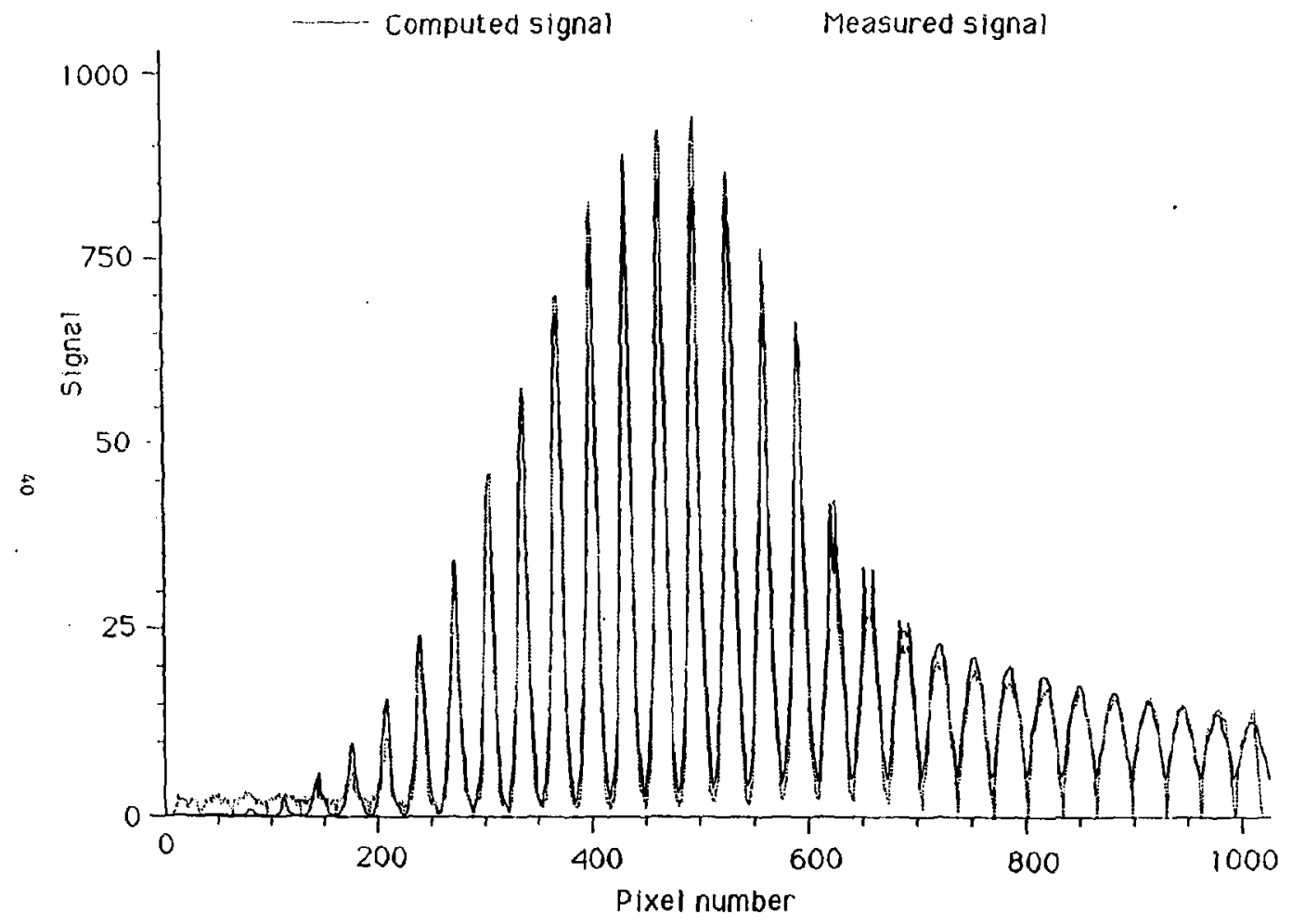

Ftgura 21 


\section{4 active channels}

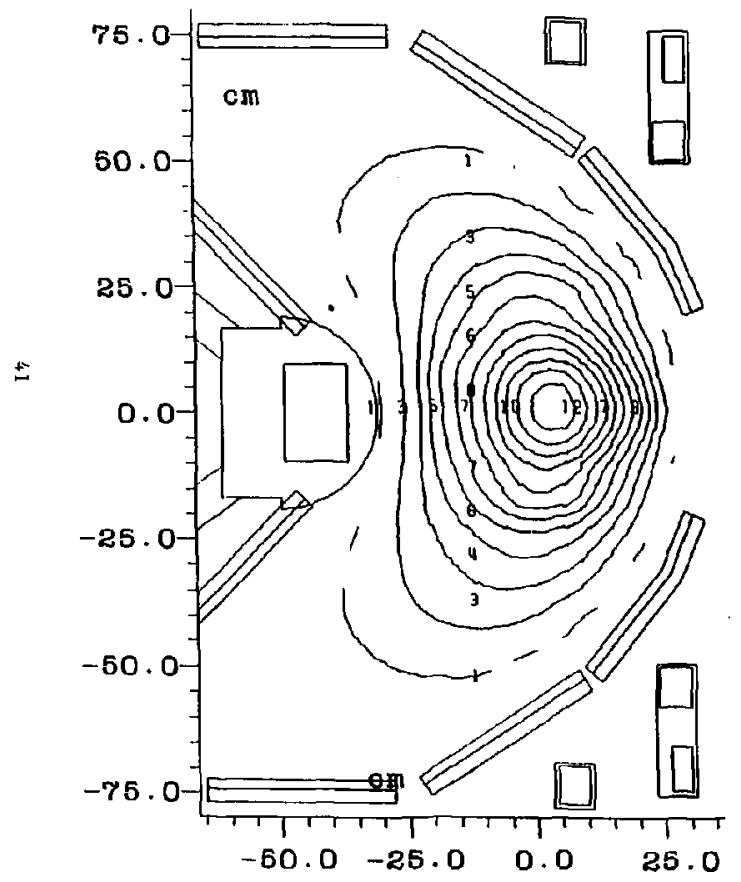

Time 520.000 msec

Processing linear

Eaission contour levels

Level I = I.000E+05

Inarement = 4.000E+05

Emission rengo

Mininun = 802 .

Haxinun $=4.033 E+08$

Averago $=1.206690 \mathrm{E}+06$

Gaussian notso statistios.

Holse lovel - 2.00

Sharpness - 14.8

RHS Std. dev. $=4.89$

Std dev, type -0

RHS nolse - 27.7

Blind notse -0.590

Nunber of cells $=218$

Humbes of lterations -

Reoont ruation tiag -

FAst HE algorithn.

Datafile Co_PARAz.late

Default jmage fiJew:26050J_620p040.D Veight rile MFAR.R

Hatrix origin

R $=-67.000 \mathrm{on}$

$\mathrm{z}=-66.000 \mathrm{~cm}$

Cell $612 e$

$R=4,000 \mathrm{~cm}$

Z $=$ 4.000 on 


\section{4 active channels}

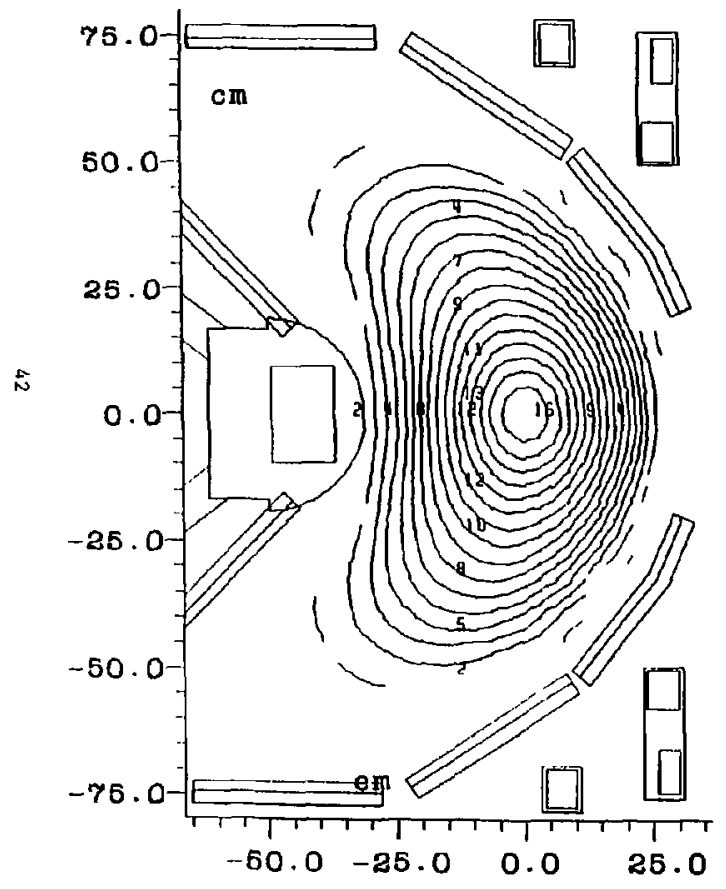

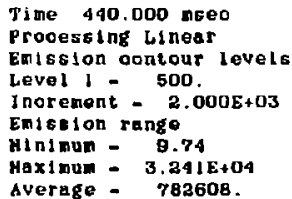

Dalaf l le GNTR_PARA.LATE

Default inage file $\mathbf{H}: 260501$ 6a09040 $r$ Velght fale Hr4R.R

Hatrix ortgin

R - -67.000 an

$z=-68.000$ an

Cell size

R. 1.000 on

$2=4.000 \mathrm{co}$ 


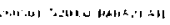

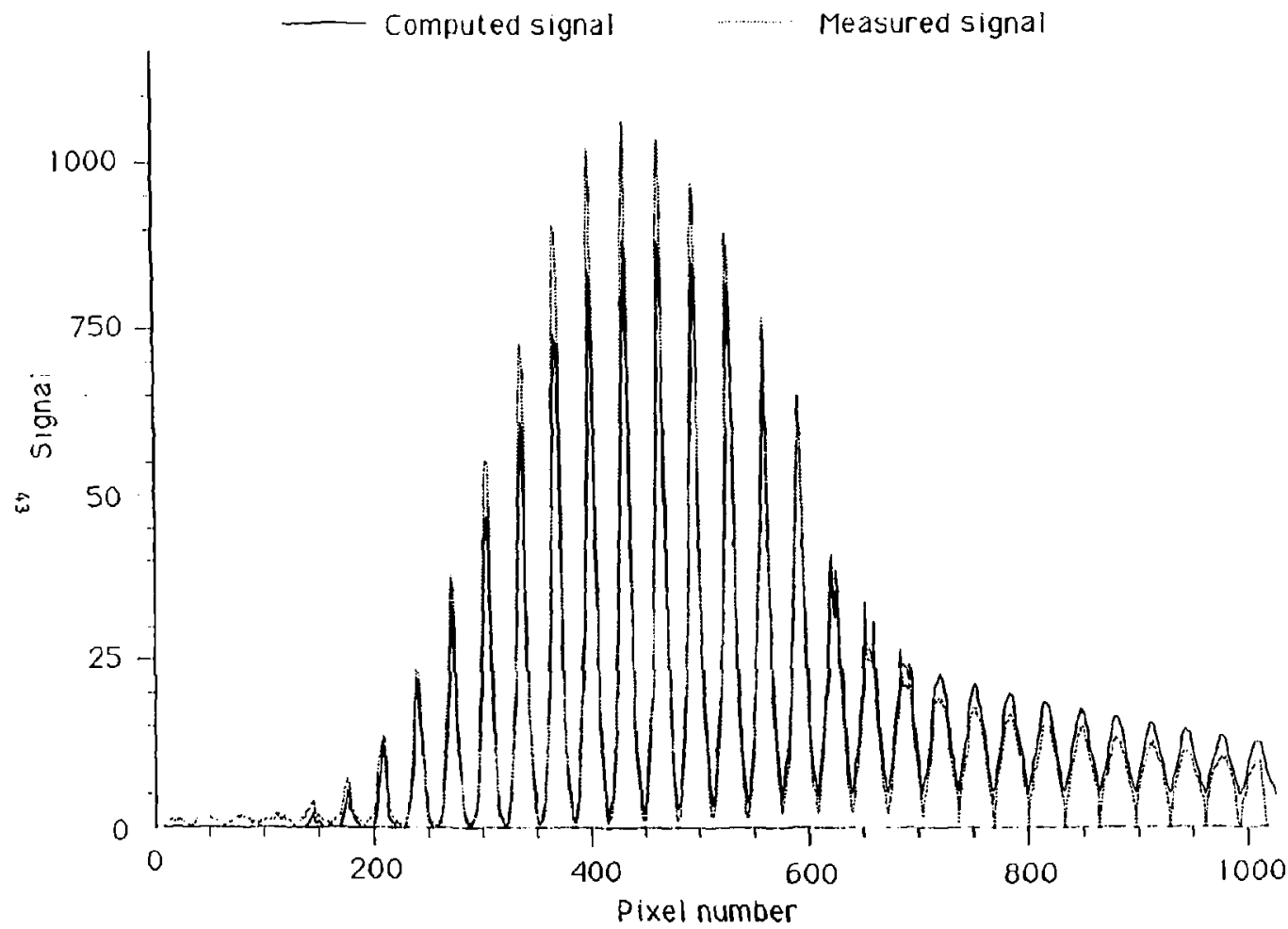

Pigure 24 


\title{
NOTICE
}

Available from:

National Technical Information Service

U.S. Department of Commerce

5285 Port Royal Road

Springfield, Virginia 22161

$703-487-4650$

Use the following price codes when ordering:

Price: Printed Copy $\mathrm{AO} 3$

Microfiche Ar1

\section{DISCLAIMER}

\begin{abstract}
This report was prepared as an account of work sponsored by an agency of the United States Goverament. Neither the United States Government not any agency thereof, nor any of their employees, matkes any warranty, express or implied, or assumes any legal habality ar responsibility for the accuracy. completeness, or usefulness of any information. apparatus, product, or process disclosed, or represents that its use would not infringe prtvately uwned righls Refer. ence herein to any specific commercial product, prucess, or service by irade name, irademark. mahufaclurer, or otherwise does nol necessarily constilute or imply its endorsement, recommendation. or favoring by the United States Government or any agency thereor The views and opinions of authors expressed hetein do not necessarily state or teflect those of the United States Government or any agency thereof.
\end{abstract}

